\title{
Trunk Robot Rehabilitation Training with Active Stepping Reorganizes and Enriches Trunk Motor Cortex Representations in Spinal Transected Rats
}

\author{
Chintan S. Oza ${ }^{1}$ and Simon F. Giszter ${ }^{1,2}$ \\ ${ }^{1}$ School of Biomedical Engineering and Health Systems and ${ }^{2}$ Department of Neurobiology and Anatomy, Drexel University, Philadelphia, Pennsylvania \\ 19129
}

Trunk motor control is crucial for postural stability and propulsion after low thoracic spinal cord injury (SCI) in animals and humans. Robotic rehabilitation aimed at trunk shows promise in SCI animal models and patients. However, little is known about the effect of SCI and robot rehabilitation of trunk on cortical motor representations. We previously showed reorganization of trunk motor cortex after adult SCI. Non-stepping training also exacerbated some SCI-driven plastic changes. Here we examine effects of robot rehabilitation that promotes recovery of hindlimb weight support functions on trunk motor cortex representations. Adult rats spinal transected as neonates (NTX rats) at the T9/10 level significantly improve function with our robot rehabilitation paradigm, whereas treadmill-only trained do not. We used intracortical microstimulation to map motor cortex in two NTX groups: (1) treadmill trained (control group); and (2) robot-assisted treadmill trained (improved function group). We found significant robot rehabilitation-driven changes in motor cortex: (1) caudal trunk motor areas expanded; (2) trunk coactivation at cortex sites increased; (3) richness of trunk cortex motor representations, as examined by cumulative entropy and mutual information for different trunk representations, increased; (4) trunk motor representations in the cortex moved toward more normal topography; and (5) trunk and forelimb motor representations that SCI-driven plasticity and compensations had caused to overlap were segregated. We conclude that effective robot rehabilitation training induces significant reorganization of trunk motor cortex and partially reverses some plastic changes that may be adaptive in non-stepping paraplegia after SCI.

Key words: cortex motor map; locomotion; muscle synergy; recovery of function; robot rehabilitation; spinal cord injury

\section{Introduction}

Cortex reorganizes after skill learning (Pascual-Leone et al., 1995; Nudo et al., 1996b; Kleim et al., 1998; Tyc et al., 2005; Tyč and Boyadjian, 2011), peripheral injuries (Sanes et al., 1988, 1990; Cohen et al., 1991; Pascual-Leone et al., 1996; Toldi et al., 1996; Rijntjes et al., 1997; Schieber and Deuel, 1997; Wu and Kaas, 1999), brain injury (Nudo and Friel, 1999; Nishibe et al., 2010; Harrison et al., 2013), or spinal cord injury (SCI) (Jain et al., 1997; Ghosh et al., 2010; Tandon et al., 2013; Moxon et al., 2014;

Received 0ct. 21, 2014; revised March 15, 2015; accepted March 26, 2015.

Author contributions: C.S.0. and S.F.G. designed research; C.S.0. performed research; C.S.O. and S.F.G. analyzed data; C.S.O. and S.F.G. wrote the paper.

This work was supported by National Institutes of Health Grants NS54894 and NS72651, the Nielsen Foundation, and the Drexel University College of Medicine Neuroengineering Strategic Plan. We thank Kavon Noorbehesht for assistance with treadmill training, animal care, and surgical support. We thank Michael Elsenbeck for partial assistance with robot training and Michael Christiansen for assistance with behavioral scoring. We thank Dr. Tim Himes for assistance with histology and Dr. Ubong Ime Udoekwere for assistance with setting up surgical and robot training protocols.

The authors declare no competing financial interests.

Correspondence should be addressed to Dr. Simon F. Giszter, Department of Neurobiology and Anatomy, Drexel University College of Medicine, 2900 Queen Lane, Philadelphia, PA 19129. E-mail: simon.giszter@drexelmed.edu.

C. S. Oza's present address: Department of Biomedical Engineering, Duke University, Room 136 Hudson Hall, Box 90281, Durham, NC 27708-0281.

DOI:10.1523/JNEUROSCI.4366-14.2015

Copyright $\odot 2015$ the authors $\quad 0270-6474 / 15 / 357174-16 \$ 15.00 / 0$
Oza and Giszter, 2014). Complete low thoracic SCI causes paraplegia, compensatory motor behavior, and significant cortical reorganization in rats (Oza and Giszter, 2014). Voluntary trunk control is crucial for postural stability and propulsion after SCI (Yang et al., 2006; Giszter et al., 2008a; Bjerkefors et al., 2009; Desroches et al., 2013). Robotic rehabilitation of the trunk is promising in human (Dobkin et al., 2003; Hidler and Sainburg, 2011; Hussain et al., 2011) and animal (Udoekwere et al., 2006; Udoekwere, 2010; Dominici et al., 2012) SCI. We showed (Oza and Giszter, 2014) that complete SCI in adult rats caused expansion of trunk motor representations and deviations from normal topographies, including increased trunk-forelimb overlap. Robot rehabilitation in adult SCI rats without hindlimb stepping caused additional shifts of trunk representation topography, beyond SCI alone, without improved function. How does trunk motor cortex reorganize with robot training in SCI rats with hindlimb stepping, in those rats that do improve function?

Spinal transection at postnatal days 0 (P0) to P6 in rats (NTX rats) allows development of autonomous lumbar stepping (Stelzner et al., 1975; Giszter et al., 1998, 2008a, 2010; Kao et al., 2009). Stepping develops without influences of descending controls and neuromodulation. Approximately $20 \%$ of NTX rats achieve independent weight support as adults, partly attributable to cortical trunk controls (Giszter et al., 1998, 2008a). Furthermore, NTX 
A Experimental Design

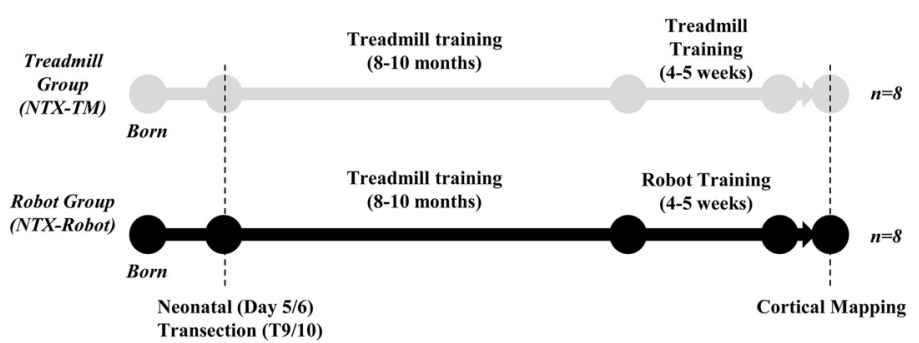

B Changes in \% weight support

C Changes in AOB scores with in NTX-Robot group
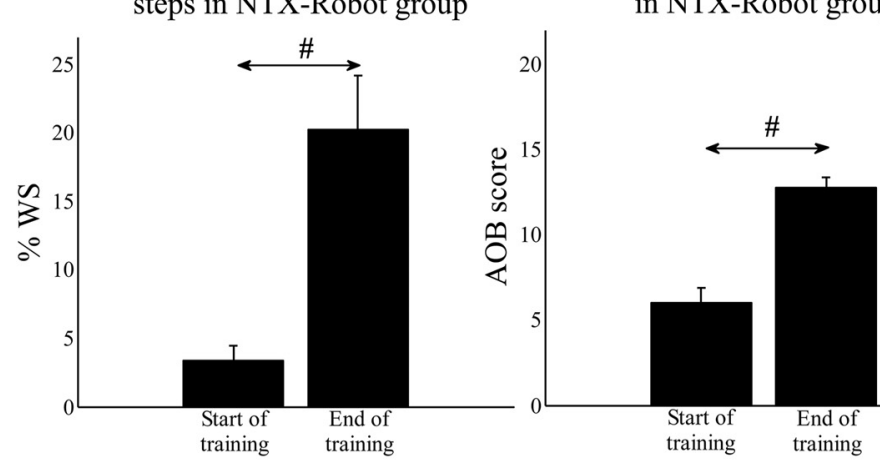

D Changes in \% Body Weight Support in NTX-Robot group

Figure 1. $\quad A$, Experimental design. $B$, Changes in \%WSS on robot support in the NTX-Robot group at the start and end of training, showing clear improvements. C, Changes in AOB scores on robot support at the start and end of training for NTX-Robot rats, showing improvements. D, Changes in \%BWS (vertical robot interaction force normalized to weight) across training days for all NTX-Robot rats. There were no significant improvements in \%WSS and AOB scores $\left(p>0.8\right.$, paired $t$ test) in the NTX-TM control rats (data not shown). ${ }^{\#} p<0.05$, paired $t$ test; data expressed as mean \pm SEM.

rats can improve leg function with robot step training (de Leon et al., 2002; Cha et al., 2007), show plastic changes in the spinal cord (Petruska et al., 2007), and alter sensory cortex after treadmill training (Kao et al., 2009, 2011). Trunk robot rehabilitation training of such rats promotes better hindlimb weight-supported stepping function (U. I. Udoekwere, C. S. Oza, and S. F. Giszter, unpublished observations). These capabilities in NTX rats provide a signpost to potential function achieved with low to no direct connectivity in the adult rat. NTX rats are also an excellent model to study the cortical plasticity associated with such recovery of function. These specific skill acquisitions may alter and drive expansion of motor representations evoked by microstimulation. Rehabilitation training after brain injury also sometimes reverses the loss of rich motor representations attributable to the injury, which correlates significantly to degree of recovery of function (Ramanathan et al., 2006).

We hypothesized that trunk robot rehabilitation that significantly improved function would also cause reorganization of trunk motor representations and enrich motor map features. To test this, we used intracortical microstimulation (ICMS) to map motor cortex in two groups of adult rats spinalized as neonates: (1) treadmill trained; and (2) robot rehabilitation treadmill trained. Our results show that robot rehabilitation that improves function enriches and alters systematically the motor topography, whereas similar treadmill-trained rats show neither effect.

\section{Materials and Methods}

Overview. All surgical and experimental procedures were performed in accordance with Institutional Animal Care and Use Committee guidelines and recommendations and with full approval. We prepared rats by spinally transecting pups of experienced dams at P5 or P6 and rearing them to adulthood. Most such postnatal NTX rats (complete injury at T8-T10) can, as adults, generate lumbar stepping motions (crude alter- nations/scissoring motions) on the treadmill without additional stimuli. Approximately $20 \%$ of these rats are also able to achieve independent (autonomous) weight support (WS rats; i.e., $>50 \%$ of steps are weight supporting) as adults. The other $80 \%$ are non-WS rats. All rats used in this study were non-WS rats, i.e., drawn from the $80 \%$ of rats without such functional weight support stepping ability. The experimental design is shown in Figure 1A. At an adult age, the non-WS NTX rats were subdivided into two groups: spinalized-treadmill trained (NTX-TM; $n=8$ ) and spinalized-robot-assisted treadmill trained (NTX-Robot; $n=$ 8). Locomotor function of NTX rats at the time of grouping was not significantly different. After training, we examined the representation of motor cortex in the two NTX groups using ICMS. We also compared map data from the two NTX groups with a group of normal rats as reported previously (Oza and Giszter, 2014).

Neonatal NTX. To obtain the data, 30 female Sprague Dawley rats were prepared to manage losses at different experimental stages (initial surgery, before weaning, after weaning, implantation, and mapping) and allow for this attrition. Each received complete SCI at T9/10 on P5 or P6. Sterile procedures were used throughout the surgery. Surgical procedures were similar to those described previously in detail (Miya et al., 1997; Giszter et al., 1998, 2008a), but we used isoflurane anesthesia instead of hypothermia. With this anesthesia, rats were transected on P5 or P6 rather than P2. Briefly, pups were placed under anesthesia and maintained with isoflurane $(0.75-1.5 \%$ mixed with oxygen), and one complete segment of thoracic spinal cord (T9/10) was completely aspirated away. The lesion cavity was filled with Gelfoam, and the incision was closed in layers. Postoperatively, pups received $0.01 \mathrm{ml}$ of $0.002 \mathrm{mg} / \mathrm{ml}$ buprenorphine subcutaneously. Thereafter, they were returned to their mothers until they reached weaning age ( $\sim 4$ weeks). During this period, their weights were monitored regularly.

Preliminary treadmill training. After weaning ( $\sim 4$ weeks of age) until an adult age ( $\sim 8-12$ months), rats received moderate unassisted treadmill training (i.e., $3-5 \mathrm{~min} / \mathrm{d}, 3 \mathrm{~d} /$ week, treadmill speed of $4-8 \mathrm{~cm} / \mathrm{s}$ ) to maintain any spontaneous developed functional recovery. In practice, we have observed that the effect is simply maintenance of function achieved 
shortly after weaning. Training sessions were video recorded periodically (once or twice a month) to get an estimate of any ongoing functional recovery.

Pelvic orthosis implantation. At adult ages ( $\sim 8-12$ months), 18 nonweight-supporting transected rats were implanted surgically with a pelvic orthosis. Previous unpublished observations from our laboratory suggest better integration of the orthosis with the bone in NTX rats if implantation is performed at least $6-8$ months after neonatal SCI. Pelvic orthosis construction and surgical techniques were similar to those described previously (Udoekwere et al., 2014). Briefly, rats were anesthetized by injecting intraperitoneally with $1.0 \mathrm{ml} / \mathrm{kg} \mathrm{KXA}$ mixture $[2.0 \mathrm{ml}$ of ketamine $(100 \mathrm{mg} / \mathrm{kg}), 1.0 \mathrm{ml}$ of xylazine $(20 \mathrm{mg} / \mathrm{kg})$, and $0.15 \mathrm{ml}$ of acepromazine $(10 \mathrm{mg} / \mathrm{kg})]$. Supplemental doses of KXA $(0.38 \mathrm{ml} / \mathrm{kg})$ were administered intraperitoneally as needed to maintain a deep level of anesthesia throughout the procedure. Bilateral incisions angled at $45^{\circ}$ and $\sim 1 \mathrm{~cm}$ caudal to the iliac crest were made, followed by blunt dissection separating the gluteus muscle with minimal tissue damage. A sterile pelvic orthosis was inserted and clamped to the iliac processes on both sides of the rat's pelvis, and sides of the implant were fastened with screws. Epoxy cement (KwikWeld; J-B weld) was applied to the middle joint at which the two sides of the pelvic implant were connected and typically set fully before the animal recovered from anesthesia.

Postoperative care. Postoperatively, rats were given $1.0 \mathrm{ml} / \mathrm{kg}$ of 0.05 $\mathrm{mg} / \mathrm{ml}$ buprenorphine subcutaneously for analgesia every $8-12 \mathrm{~h}$ for $48 \mathrm{~h}, 0.5 \mathrm{ml} / \mathrm{kg}$ prophylactic antibiotics (diluted $3.4 \mathrm{ml}$ of sterile water with $1 \mathrm{~g}$ of ampicillin vial) subcutaneously once a day for $7 \mathrm{~d}$, and 5-10 $\mathrm{ml}$ of lactated Ringer's solution subcutaneously for $7 \mathrm{~d}$. Rats were monitored twice daily for skin lesions, autophagia, or other health concerns.

Experimental training. After preliminary treadmill training for $\sim 8$ months, the rats were then assigned randomly to the two groups: NTX-TM and NTX-Robot. There were no statistically significant differences in the age, weight, and function between the two groups of rats at the time of grouping. The treadmill-trained group continued to be trained on the treadmill but usually at higher intensity, whereas robottrained rats started robot training 10-14 d after pelvic implant surgery. Observations from our laboratory show that no significant improvement of function in non-weight-supporting NTX rats occurs if 6-8 months or more of moderate treadmill training is followed up by intense treadmill training ( $20 \mathrm{~min} / \mathrm{d}$ for $5 \mathrm{~d}$ /week for $4-6$ weeks). The NTX-TM group in this study included rats that either continued moderate treadmill training or intense treadmill training after $8-10$ months of moderate treadmill training. Treadmill-trained rats were video recorded for assessment of function once a week. There were no significant differences between the moderately and intensely treadmill-trained rats in their function and no additional improvements in function. Robot-trained rats were trained with a cantilevered phantom haptic robot (Sensable Devices) that applied isotropic elastic forces through an implanted orthosis at the pelvis during quadrupedal treadmill locomotion $(20 \mathrm{~min} / \mathrm{d}, 5 \mathrm{~d} /$ week for 4-5 weeks) similar to that described previously (Udoekwere et al., 2006; Hsieh and Giszter, 2011; Oza and Giszter, 2014). Isotropic elastic force fields were applied. There was a $5 \mathrm{~s}$ graded ramp period before stiffness (gain) for force applied reached its maximum value at the beginning of each training day to avoid initial jerk. The training elastic fields were applied with equilibrium position set such that the trunk posture and carriage height of the spinalized rat is similar to that of a normal adult intact rat (stiffness of $45 \mathrm{~N} / \mathrm{m}$ in rostral-and-caudal, medial-and-lateral, and dorsal-and-ventral directions). This strategy alters trunk kinematics and ground reaction forces during stance while leaving the limb swing phase unconstrained and thereby allowing integrated training of both the trunk and hindlimb and their interactions. Robot data (position, force, and velocity for $x, y$, and $z$ directions) were sampled at $1 \mathrm{kHz}$, video recorded continuously throughout all trials, and saved on local hard disk for analysis.

Locomotor assessment. Hindlimb stepping was assessed from the recorded video using the AOB scale (Antri et al., 2002) and percentage weight-supported stepping (\%WSS) scores. The AOB scale is a modified Basso-Beattie-Bresnahan (Basso et al., 1995)-type scale designed by Antri, Orsal, and Barthe that scores rats on frequency, amplitude, and coordination of hindlimb stepping motions and is divided into four levels. Level 1 (score of $0-1$ ) corresponds to animals unable to support their body weight with their hindlimbs and unable to step. Level 2 (score of 2-9) corresponds to rhythmic movements of hindlimbs without any body weight support. Level 3 (score of 10) corresponds to consistent rhythmic movements with dorsal foot placement and occasional body weight support. Level 4 (score of 11-22) corresponds to rhythmic movements of hindlimbs with plantar paw placement with the possibility of body weight support.

Hindlimb steps were also classified and counted as weight supporting or non-weight supporting over the same time segment used for AOB scoring, in a procedure similar to our previous work (Miya et al., 1997; Giszter et al., 1998, 2008a). Briefly, a hindlimb step was considered as weight supporting if both hindlimbs alternated autonomously and were seen to be raised above the surface of the treadmill with no contact of the belly, knee, or hip with the treadmill during the swing and stance phases of the hindlimb step cycle. A step cycle was counted as a movement of a limb that included ankle extension (stance) and flexion (swing). Weightsupporting steps included successive stance and swing phases with hindquarter support. Plantar foot placement was not required, and dorsal or "knuckle" stepping was permitted. \%WSS was calculated by counting the number of weight-supported steps divided by the total steps within a scoring interval.

We first assessed \%WSS and AOB scores during treadmill locomotion in all the rats at the time of random assignment to the two experimental groups (i.e., before any robot training). Robot-trained rats were assessed for $\%$ WSS and AOB scores at the start of robot training (first day) and at the end of robot training (last day) during treadmill locomotion in the presence of robot support (i.e., the robot was connected and the elastic field was active). Because day 1 may involve acclimation to the robot, we also assessed function on day 4 of robot training. We found that results and significant statistics were similar regardless of whether day 1 or 4 were used, and day 1 and 4 were not significantly different from each other, although a trend of improvement was seen (see Results). Treadmill-trained rats were scored for \%WSS and AOB scores at similar stages of their training during treadmill-only locomotion.

Robot-trained rats were also evaluated by examining changes in percentage body weight support (\%BWS) provided by the robot over the duration of training. \%BWS for each day was calculated as vertical robot interaction force data converted to Newtons and normalized to weight (Newtons) of the animal on that day and expressed as percentage.

ICMS mapping. After training, we used ICMS to map the motor cortex representations of all NTX rats, in a manner similar to techniques described previously (Giszter et al., 1998; Oza and Giszter, 2014). Briefly, dexamethasone $(5 \mathrm{mg} / \mathrm{kg})$ was administered intraperitoneally several hours before the surgery to control blood pressure and brain swelling. Then, rats were anesthetized intraperitoneally with $1.0 \mathrm{ml} / \mathrm{kg} \mathrm{KXA} \mathrm{mix-}$ ture $[2.0 \mathrm{ml}$ ketamine $(100 \mathrm{mg} / \mathrm{kg}), 1.0 \mathrm{ml}$ xylazine $(20 \mathrm{mg} / \mathrm{kg})$, and 0.15 $\mathrm{ml}$ acepromazine $(10 \mathrm{mg} / \mathrm{kg})]$, followed by supplemental doses of ketamine $(0.24 \mathrm{ml} / \mathrm{kg})$ only. Dorsal and ventral trunk skin incisions were made, and the site of injury was identified and confirmed through palpation for missing vertebrae. Nine bipolar patch electrodes (for abdominal muscles: rectus abdominus, right and left external obliques) and six bipolar ball electrodes (for dorsal trunk: right and left longissimus) were placed at three segmental levels: (1) midthoracic (rostral to injury); (2) low thoracic (caudal to injury); and (3) upper lumbar (caudal to injury). Then, the rat's head was placed in the stereotaxic frame, and bregma and lambda were noted. A window in the skull surface $(\sim 10 \times 8 \mathrm{~mm})$ and dura was removed to expose the cortical surface. Care was taken to electrically isolate the animal for stimulation with ICMS. Core body temperature was maintained at $\sim 37^{\circ} \mathrm{C}$ using an overhead heating lamp. Cortical surface was kept moist with a shallow saline bath and cotton or gauze reservoir. Fine stainless steel electrodes $(\sim 10 \mathrm{M} \Omega$; initial impedance at 1 $\mathrm{kHz}$; shank diameter, $125 \mu \mathrm{m}$; tip, $<1 \mu \mathrm{m}$ diameter; exposed tip, $\sim 5$ $\mu \mathrm{m}^{2}$; FHC) were used. Mapping penetrations were made vertically to the cortical surface and were arrayed across the motor cortex in a continuous $0.5 \mathrm{~mm}$ grid starting on the bregma line. Before stimulating at each cortex location, limbs were extended. Stimuli were applied as $0.2 \mathrm{~ms}$ total duration constant-current balanced biphasic pulses with cathodal current leading, at $333 \mathrm{~Hz}$ in trains of $300 \mathrm{~ms}$ duration. Typical current 
values were between 60 and $80 \mu \mathrm{A}$ and never exceeded $100 \mu \mathrm{A}$ and were similar between the two experimental groups. Pulse waveforms were monitored throughout the surgery with a Tektronix oscilloscope to examine voltage drop across a $10 \mathrm{k} \Omega$ resistor interposed in series between the preparation ground and the stimulator. Electrodes were replaced if pulse shapes altered radically or desired currents (voltage drops across resistors) were not observed. At each location in the cortex, the stimulation electrode was first lowered to a depth of $\sim 1500 \mu \mathrm{m}$, and responses were checked. Slight adjustments (approximately $\pm 250-400 \mu \mathrm{m}$ ) were made in the depth to identify the strongest response. A site was considered to have a positive response if we observed consistent ICMS-induced motor responses (nonfacial), such as movements of limbs at any joint or neck or electromyography (EMG) muscle responses for trunk. For all positive response sites whether trunk was active or not, trunk EMG data were recorded using differential amplifiers (model 1700 differential amplifier; A-M Systems) and a analog-to-digital data acquisition system (Digidata 1320; Molecular Devices). EMG signals were amplified with a gain of 1000 and sampled at $1 \mathrm{kHz}$. At each positive response site, all stimulation-evoked movements and muscle responses were noted during surgery. If we encountered more than three negative sites in succession in the presumed nonfacial motor cortex areas, we returned to a region close to a previously positive site and checked for responses (approximately within $100-250 \mu \mathrm{m}$ ). If this site was also nonresponsive, we terminated the experiment.

Histology. After cortical mapping, spinalized rats were deeply anesthetized with $3 \mathrm{ml}$ of Euthasol and perfused intracardially with $0.9 \%$ physiological saline, followed by $4 \%$ buffered paraformaldehyde (PFA) to fix spinal tissue. Next day, spinal cord tissue was extracted and blocks were preserved in $4 \%$ buffered PFA for $3 \mathrm{~d}$, soaked in $30 \%$ sucrose for 1 week, and embedded in M1 embedding matrix (Thermo Fisher Shandon) and stored in $-75^{\circ} \mathrm{C}$ refrigerator. Blocks containing the lesion were cut in serial, parasagittal $25 \mu \mathrm{m}$ sections. Nissl myelin stain and serotonin immunohistochemical stain with 3-3' diaminobenzidine tetrahydrochloride were used to examine the completeness of spinal transection. Typically, we observed cord end separation and absence of Nissl body and myelin staining at the transection site and absence of serotonergic fibers below the injury. All spinalized rats had histologically complete lesions and satisfied these criteria (data not shown), consistent with our previous results (Miya et al., 1997; Giszter et al., 1998, 2008a) with similar surgical transection.

Data analysis. We examined motor cortex representations derived from ICMS mapping in the two groups of adult rats spinalized as neonates and also compared these with a group of normal rats. For several rats, we mapped both sides of the cortex, but for statistical comparisons, we only considered the side of the cortex with richer (denser and larger) trunk representation in both groups. Our selection process reduced motor map variance for comparisons, and, in some instances, a second cortex side was not available in data. To analyze map data, we generated a matrix of data per rat for all sites stimulated in the selected side of the motor cortex. The first two columns in the matrix corresponded to the medial-and-lateral $(x)$ and rostral-and-caudal $(y)$ cortex coordinates with bregma considered to be at $(0,0)$. Subsequent columns were filled with response types ( 0 , no response; 1 , positive response) for 15 trunk muscle segments, forelimb and hindlimb movements. Positive responses for trunk EMGs noted during the surgery were further verified by comparing the prestimulus rectified and integrated EMG activity (baseline) to poststimulus rectified and integrated EMG responses for each trunk recording channel for each spatial location in the cortex in each rat from the saved data. Only EMG responses that were consistent across multiple stimuli were considered. Sites with two or more response points (e.g., forelimb and trunk) were counted for both representations ( 1 for forelimb and 1 for all trunk recording sites that were coactive at that point in the cortex). Thus, each rat had a binary matrix with rows that corresponded to spatial locations in the cortex and columns that corresponded to 15 trunk EMG channels, forelimb and hindlimb. Once we had this "binary" matrix of muscles recruited for each site in each rat, we determined different map features in each rat. For example, the size of the nonfacial motor cortex was determined by calculating the total number of sites in the cortex in which we obtained a positive motor response for forelimb, trunk, or neck movements. Because we also compared spinalized rats with normal intact rats, we did not consider exclusive hindlimb sites in determining the size of the nonfacial motor cortex from normal rats. This was because it would bias the normalization for normal rats because the neonatal transected rats have no hindlimb representation. This ensured that there were no a priori significant differences in the size of the nonfacial motor cortex in normal and transected rats.

We used information theoretic measures (entropy and mutual information) to examine richness and complexity of spatial motor representation in the cortex. These measures are useful because they are metrics that capture the ideas that (1) spatial representation of many different muscle combinations at different sites may be needed in gain-of-function/skill development and (2) some core synergies associated with a skill may be represented more strongly and at more sites after skill acquisition. We use these information measures in our binary map data to infer the varieties and novelties of synergy (high entropy implies more types of synergy or muscle combinations), as well as the degree of correlation and consistency in synergy representation among different motor cortex sites (high mutual information implies more consistency in synergy representation and more synergies repeated across multiple sites when taken as a whole). We calculated Shannon's entropy $(H)$ using the following formula (MacKay, 2003; Cover and Thomas, 2006):

$$
H=-\sum_{i=1}^{n} P(i) \times \log _{2} P(i)
$$

where $n$ is the number of discrete categories, and $P(i)$ is the probability distribution of observing category $i$. Because we had a binary matrix representation of the motor maps for each rat (15 trunk EMG recording sites $\times$ cortex motor sites), we calculated the entropy associated with each trunk EMG channel (i.e., for each of the 15 columns in the matrix, because we had a total of 15 trunk EMG channels recorded) under the assumption of site independence (i.e., assuming independent fair "coin tosses" at each site). Total cumulative entropy for all trunk EMG channels was calculated as the sum of entropies for these 15 columns in a rat. Because every rat was mapped and ordered systematically and similarly, the channel entropy measured the random variations of the channel across the motor map in a comparable manner among rats. If a channel EMG was recruited at every site or at no sites, the entropy would be 0 , with the entropy measure between these extremes following an inverted $\mathrm{U}$ function, peaking where a repeated fair coin toss would peak. NTX-TM rats had on average of $\sim 1.9$ trunk EMG responses (of a possible 15) per cortex site, whereas NTX-Robot rats had $\sim 3.2$. Neither was near the peak of a completely unbiased coin toss and both were on the ascending arm of the inverted $U$ function. This metric thus measured the variation and unbiased randomness in the map. These entropy estimates were then averaged for all rats in a group. Similarly, total cumulative entropy for a particular trunk segmental level was calculated as the sum of entropies for the five columns in the matrix corresponding to that segmental level (i.e., columns 1-5 for midthoracic, 6-10 for low thoracic, 11-15 for lumbar).

We also examined the entropy associated with sites and areas in the cortex for trunk representations [i.e., we calculated entropy using the trunk column elements (i.e., channels 1-15) for each row in the matrix, in which each row represented a cortex site, starting at row 1 through the size of the nonfacial motor cortex] and defined this as a "site entropy." Then, site entropies for regions of cortex were derived. Regions were defined broadly by location relative to bregma (two regions: above bregma and at/below bregma). The cortical sites (points stimulated) were sorted into the two regions classified by location. In other words, we calculated the sum of cortex stimulation site entropies for locations above bregma and for locations at/below bregma for each rat and then averaged these for all rats in a group. Higher entropy was again taken as a measure of richer motor representations in the cortex. These entropy measures were used as metrics of cortical change. It should be noted that they are not perfect unbiased estimates, in a classical information analysis, given the numbers of rats and sites used.

We examined mutual information between different trunk EMG channels in each rat to examine consistency of muscle channel recruit- 
ments together. The mutual information is effectively a correlation metric among the map matrix columns. Mutual information $(M)$ between any two trunk EMG channels was calculated using the following formula (MacKay, 2003; Cover and Thomas, 2006):

$$
M(x, y)=H(x)+H(y)-H(x, y),
$$

where $x$ and $y$ are any two trunk EMG channels, and $H$ is entropy (Eq. 1). The mutual information matrix in each rat is a symmetric square matrix $(15 \times 15$ because we had 15 trunk EMG channels) with diagonals $[M(x, x)]$ corresponding to the mutual information of a trunk channel $(x)$ with itself, which is equal to entropy of $x$. Cumulative mutual information in each rat was considered as the lower diagonal half sum of the mutual information matrix in each rat with the diagonals subtracted. We next calculated the so-called coefficients of constraint ( $C$, or uncertainty coefficients) and here have termed this "normalized mutual information." We did this in the following way (Press et al., 2007):

$$
\begin{aligned}
& C(x, y)=\frac{[H(x)+H(y)-H(x, y)]}{H(y)}, \\
& C(y, x)=\frac{[H(x)+H(y)-H(x, y)]}{H(x)},
\end{aligned}
$$

where $x$ and $y$ are any two trunk EMG channels, and $H$ is entropy (Eq. 1). Thus, the normalized mutual information matrix is a square but not symmetric matrix with all diagonals equal to 1 . We calculated the cumulative normalized mutual information (with diagonals subtracted) in each and averaged across rats in a group.

Statistical analyses. To examine the effects of robot training on trunk cortical reorganization and the chosen metrics, we compared the two groups of spinalized rats using two-tailed (unless otherwise stated) $t$ tests or Wilcoxon's rank-sum tests. For multiple group comparisons (normal and the two spinalized groups), we used one-way ANOVA or KruskalWallis tests, followed by Bonferroni's corrections of any post hoc comparisons. For functional recovery analysis, linear regression was used to measure improvements in \%BWS derived from robot data with training days in the robot-trained group. Paired $t$ tests or Wilcoxon's signed-rank tests were used to compare changes in behavioral AOB scores and \%WSS scores at the beginning and end of training. For all statistical tests, a $p$ value $<0.05$ was considered significant, and the decision to use parametric or nonparametric tests was based on the outcome of the Lilliefors test. Figures that show statistically significant results have symbols that correspond to a particular test used (\# for paired $t$ test; ${ }^{\star}$ for unpaired $t$ test; ${ }^{* *}$ for Wilcoxon's rank-sum test), and all data are expressed as mean \pm SEM. All data analysis was done using custom scripts in MATLAB R2009b (MathWorks).

\section{Results}

We examined motor cortex representations derived from ICMS mapping of NTX rats, initially possessing poor weight support, which were either NTX-TM $(n=8)$ or NTX-Robot $(n=8)$. After preliminary treadmill training for $\sim 8$ months, spinalized rats were assigned randomly to two groups: NTX-TM and NTXRobot. There were no significant differences in the age between the two groups of rats at the time of grouping. For comparison purposes, we also include data from a normal rat group $(n=8)$ as reported previously (Oza and Giszter, 2014). Standard motor maps were generated at $60-80 \mu \mathrm{A}$ with longer stimulation pulse trains $(300 \mathrm{~ms})$ with the goal of allowing the greatest opportunity for temporal facilitation of activity elicited by microstimulation and minimizing the possibility of false negatives (Fig. 2). As reported previously (Giszter et al., 1998; Oza and Giszter, 2014), our choice of stimulation parameters did not alter general features of motor maps in normal rats and were consistent with published data of others (Donoghue and Wise, 1982; Neafsey et al., 1986; Frost et al., 2013). Our results fall into two main categories: (1) the effect of robot training on the reorganization of trunk motor representation (area and location); (2) the effect of robot training on the "richness" of trunk motor representations within these areas. We use the term richness to convey the variety and density (or degree of coactivation) of trunk motor representations and the synergistic relationships between different trunk segments represented in the ICMS activations of motor cortex.

\section{Locomotor recovery with training}

At the time of assignment to groupings, most NTX rats had $0 \%$ weight-supporting steps, with the exception of one rat in the NTX-TM group with $12 \%$ weight-supporting steps and one rat in NTX-Robot group with 15\% weight-supporting steps. These exceptions were well below the $50 \%$ weight-supported stepping criterion we use to classify NTX rats as weight supporting. Average AOB scores were $4.9 \pm 1.2$ for NTX-TM and $5.2 \pm 1.4$ for NTX-Robot. Thus, NTX rats in both groups during treadmillonly locomotion had some autonomous lumbar limb motion alternations, and there were no significant differences between the two groups at the time of the initial random grouping $(p>$ $0.8, t$ test). Consistent with our previous findings (U. I. Udoekwere, C. S. Oza, and S. F. Giszter, unpublished observations), when compared with the first day of training, NTX-Robot rats significantly improved locomotor function on the last day of training, as seen by an increase in AOB (Fig. 1C) and \%WSS scores (Fig. $1 B$ ) in the presence of robot support (i.e., the robot was connected and the elastic field was active) and a decrease in \%BWS provided by the robot across days of training (Fig. 1D). These results remained significant when we compared function from day 4 of training with the last day of training. We did this to allay any concern that the first day of training may involve stressful acclimation to the robot and significantly diminished function. In practice, day 1 and day 4 did not differ significantly from each other, although day 4 was slightly improved, consistent with the overall trends. Robot rehabilitation helped the spinalized rats achieve mechanical states that they never achieved alone because they lacked autonomous hindlimb weight support. The framework allowed unconstrained swing with altered stance and trunk kinematics and an enhanced integration of trunk and hindlimb motions, resulting in translation of autonomous stepping motions into balanced weight-supporting steps (Fig. $1 B)$. There were no significant improvements in \%WSS and AOB scores ( $p>0.8$, paired $t$ test) during treadmill-only locomotion in treadmill-trained rats (data not shown).

\section{Effect of training on trunk motor area}

Exemplar motor maps from a rat in each group are shown in Figure 2. Unsurprisingly, none of the NTX rats had any hindlimb motor representation in the cortex.

\section{Total trunk motor area}

We first calculated total trunk area in groups (total spatial points in the motor cortex in which any trunk motor response was obtained per rat) and expressed trunk area as a percentage of nonfacial motor cortex (the nonfacial area is the total spatial location points in the cortex in which we obtained motor responses for forelimb, neck, or trunk). There were no significant differences in the size of the nonfacial motor cortex between normal (34.12 \pm 2.24), NTX-TM $(33.4 \pm 2.6)$, and NTX-Robot $(35.6 \pm 2.9)$ rats (mean \pm SEM response points, $p=0.83, F_{(2,21)}=0.19$, one-way ANOVA). Normalized trunk area was also not significantly different between the two groups of spinalized rats $(p=0.68, t$ test; Fig. $3 A)$ or between all the injured and normal rats $(p=0.17$, $F_{(2,21)}=1.94$, one-way ANOVA). However, if we included 

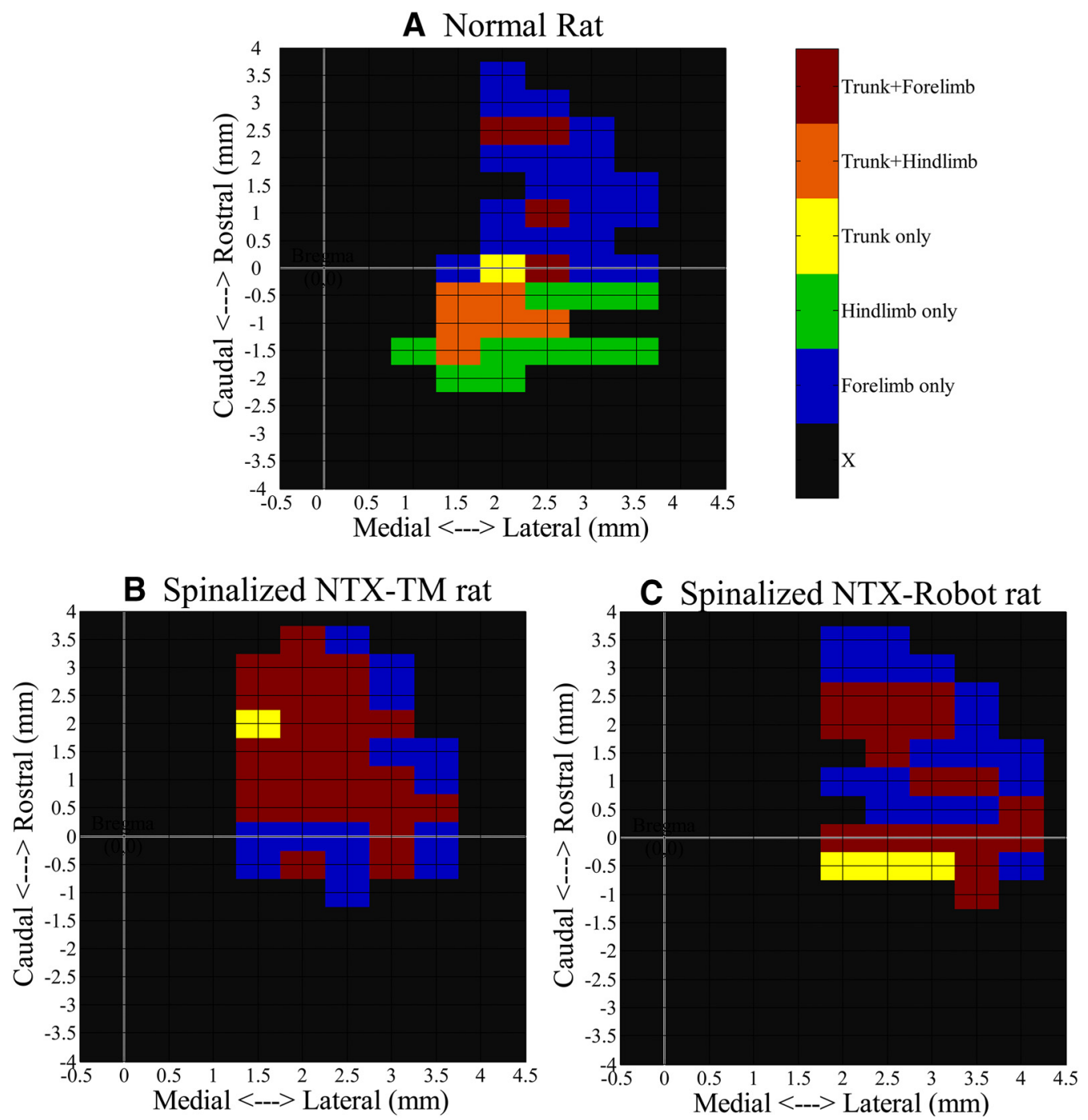

Figure 2. Comparison of example motor cortex maps from normal and adult rats spinalized as neonates. Maps show cortical areas from which forelimb, hindlimb, and trunk musculature were recruited at $60-80 \mu \mathrm{A}$ currents. Rostral is at the top of the map, and bregma is at $(0,0)$. Numbers on the axis represents distance in millimeters. For comparison purposes, all maps are presented as the right cortex shown in the same orientation. Note the different shades for trunk representation as it overlaps with other regions. $X$, No nonfacial motor response. $\boldsymbol{A}$, Normal rat; $\boldsymbol{B}$ Spinalized NTX-TM rat; C, spinalized NTX-Robot rat.

hindlimb motor sites in the calculation of the nonfacial motor cortex size in normal rats, then (and only then) we found (not surprisingly) that both spinalized groups had significantly larger normalized trunk motor areas ( $p<0.014$, each $t$ test). The absolute number of spatial locations in the cortex in which we obtained a trunk motor response was slightly larger in the NTXRobot group $(17.9 \pm 3.1)$ compared with the NTX-TM group (15.1 \pm 2.1$)$, but again the differences were not significant (mean \pm SEM response points, $p=0.47, t$ test). Therefore, robot training of NTX rats did not alter total trunk motor cortex area compared with treadmill-trained control rats, and the trunk fraction of the nonfacial motor cortex was not altered compared with normal rats unless the hindlimb cortex was included for normal rats [similar to reports for NTX rats of differing ability (Giszter et al., 1998)].

\section{Trunk motor area by segmental levels}

We next examined the effect of spinalization and training on the motor representation of trunk segmental levels both rostral and caudal to the SCI. We recorded EMGs from five muscles (ipsilateral and contralateral external obliques, longissimus, and rectus abdominus), each recorded at three segmental levels: (1) midtho- racic (rostral to the injury); (2) low thoracic (caudal to the injury); and (3) upper lumbar (caudal to the injury). Thus, we had a total of five muscle EMG recording sites at each of the midthoracic, low thoracic, and lumbar trunk segmental levels. The cortex area, which had representations of a given segmental level, was expressed as a percentage fraction of the nonfacial motor cortex. Motor cortex sites with coactivation of multiple segmental levels (e.g., both midthoracic and low thoracic) were counted as contributing area to both types of level representations (Fig. $3 B)$. For midthoracic-level representations, there were no significant differences between the two groups of NTX rats $(p=0.66$, $t$ test). However, the normal rat group had significantly lower midthoracic-level representation area compared with the two NTX spinalized groups $\left(p=0.005, F_{(2,21)}=6.79\right.$, one-way ANOVA with Bonferroni's-corrected post hoc comparisons). With the exception of one rat in the NTX-TM group, all transected rats showed consistent representation for low thoracic trunk segment levels (which were below the level of injury). NTXRobot rats also showed a significant increase in area for low thoracic level trunk motor area compared with NTX-TM rats $(p<$ 0.002 , $t$ test; Fig. $3 B$ ). Additionally, the normal rat group was also 


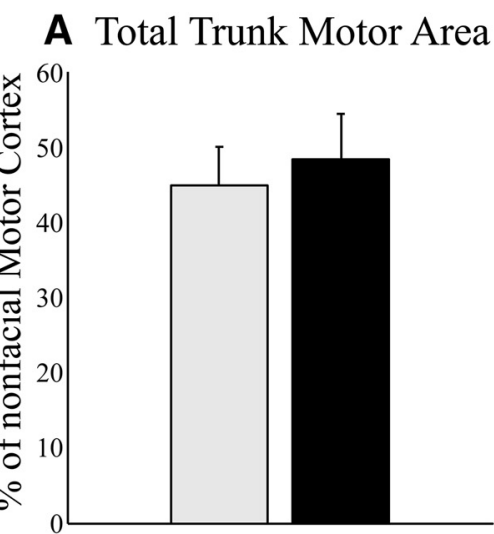

\section{B Trunk Motor Area by Segments}

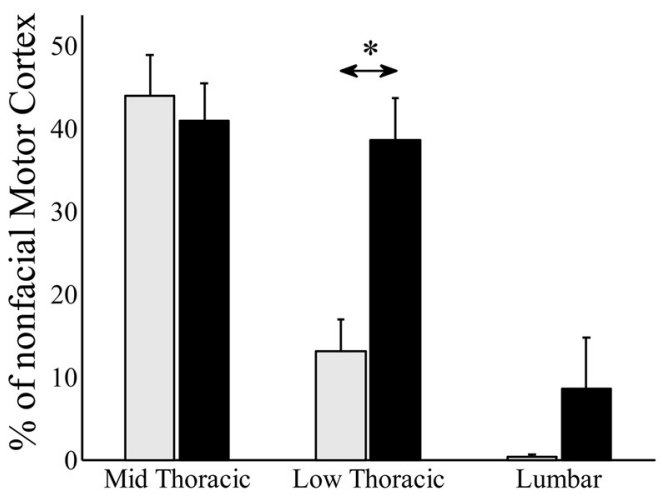

\section{Percentage of Trunk Motor Cortex for Rostral and Caudal Trunk Segments}
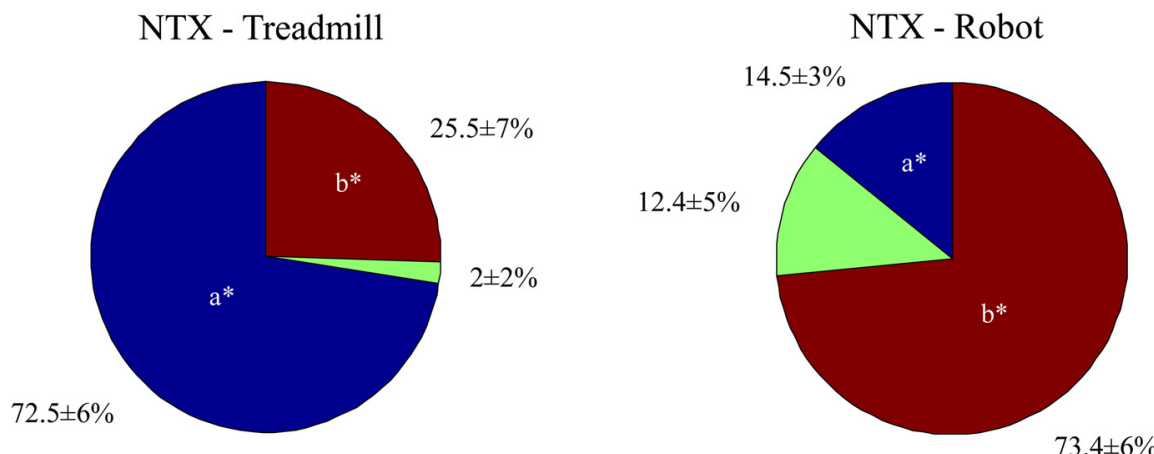

Rostral Only $\square$ Caudal Only $\square$ Rostral + Caudal

D Rostral Trunk Motor Area

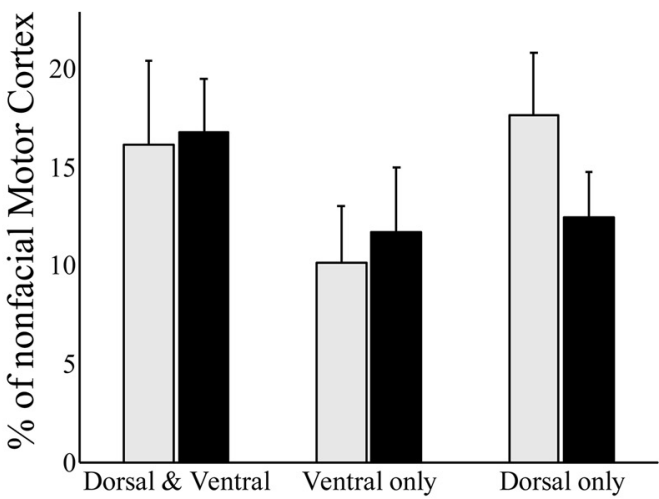

E Caudal Trunk Motor Area

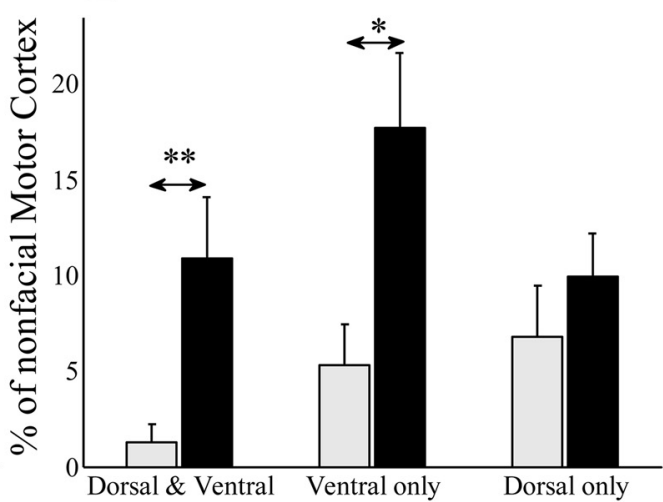

NTX - Robot

Figure 3. Trunk motor area in both spinalized groups. $A$, Normalized total trunk motor area was calculated as the number of sites in the cortex in which any trunk motor response was obtained divided by the total nonfacial motor cortex sites and expressed as a percentage (in which nonfacial motor cortex equals the total number of sites in the cortex in which forelimb, neck, or trunk motor response was obtained). No significant difference was found between the two spinalized groups. $\boldsymbol{B}$, Normalized segmental trunk motor area for midthoracic (low thoracic or lumbar) calculated as the number of sites in the cortex in which any midthoracic (low thoracic or lumbar) trunk motor response was obtained divided by the size of nonfacial motor cortex and then expressed as a percentage. Sites with coactivation of multiple segments (e.g., both midthoracic and low thoracic) were counted as contributing to both representations. The low thoracic trunk area in the NTX-Robot group is significantly larger than the NTX-TM group. C, Total trunk motor representation divided into rostral (midthoracic) only, caudal (low thoracic and/or lumbar) only, and rostral-and-caudal coactive, each expressed as a percentage of total trunk motor representation. Rostral-and-caudal coactive areas are significantly larger and rostral-only trunk areas significantly smaller for the NTX-Robot group compared with the NTX-TM group. Rostral (midthoracic) trunk area (D) and caudal (low thoracic) trunk area $(\boldsymbol{E})$ are shown each divided into dorsal-and-ventral coactive, ventral-only, and dorsal-only representations. No significant differences were found between the two groups for any rostral trunk area (D). Dorsal-and-ventral overlap and ventral-only representation at the low thoracic level are significantly larger in the NTX-Robot group than the NTX-TM group (E). Significant increase for dorsal-and-ventral overlap and ventral-only representation at the low thoracic level in the NTX-Robot group compared with the NTX-TM group. ${ }^{*} p<$ $0.05, t$ test; ${ }^{* *} p<0.05$, Wilcoxon's rank-sum test; data expressed as mean \pm SEM. 
significantly different from NTX-TM rats in their low thoracic segmental area $\left(p=0.005, F_{(2,21)}=11.35\right.$, one-way ANOVA with Bonferroni's-corrected post hoc comparisons), but no differences were found between the normal and NTX-Robot groups for this low thoracic segmental area. If we normalized and expressed the low thoracic trunk motor area as a percentage of total trunk motor area, we again found large and significant differences between the NTX-Robot $(80 \pm 4.2 \%)$ and NTX-TM $(27.5 \pm 7 \%)$ groups (data not shown; $p<0.0001, t$ test). Because three of eight robot-trained rats had motor representation of lumbar trunk but only one of eight treadmill-trained rats did, we did not perform statistical comparisons between the two spinalized groups. The normal group was significantly different from the two spinalized groups for the lumbar trunk representation $\left(p=0.0007, F_{(2,21)}=\right.$ 14.47, Kruskal-Wallis test with Bonferroni's-corrected post hoc comparisons). In summary, robot training of NTX rats significantly increased cortical motor representations for the low thoracic trunk level, to levels seen in normal rats.

\section{Overlap and coupling of trunk motor representations by segmental levels}

We next focused on more detailed analysis to examine overlap and coupling of trunk muscles in motor representations, compared by segmental levels in the two NTX spinalized groups. These comparisons relate to rostrocaudal couplings in the cortical controlled trunk actions. We divided the total trunk representation into three categories: (1) rostral-only (midthoracic alone); (2) caudal-only (low thoracic and/or lumbar but no midthoracic); and (3) rostral-and-caudal coactive (Fig. 3C). NTX-Robot rats showed a significantly larger portion of their trunk motor cortex devoted to coactivated rostral-and-caudal trunk sites $(73.4 \pm 6 \%)$ compared with that in NTX-TM rats $(25.5 \pm 7 \%$; $p<0.0002, t$ test). This difference also resulted in a significant reduction in the rostral-only trunk representation in NTX-Robot rats compared with NTX-TM rats ( $p<0.00001, t$ test). However, caudal-only trunk representation was also larger in NTX-Robot rats compared with NTX-TM rats, but this did not achieve significance ( $p=0.08, t$ test). Additionally, the normal rat group was significantly different from NTX-TM rats for rostral-andcaudal $\left(p=0.0001, F_{(2,21)}=14.69\right.$, one-way ANOVA with Bonferroni's-corrected post hoc comparisons) and rostral-only $\left(p<0.00001, F_{(2,21)}=37.54\right.$, one-way ANOVA with Bonferroni's-corrected post hoc comparisons) trunk representation. However, no differences were found between the normal and NTX-Robot groups for these comparisons. The normal rat group was significantly different from both NTX-TM and NTXRobot groups for caudal-only trunk representation $(p=0.003$, $F_{(2,21)}=8.45$, one-way ANOVA with Bonferroni's-corrected post hoc comparisons). Thus, together, robot training of NTX rats resulted in a reduction of rostral-only trunk motor representations in the cortex, coupled with a significantly larger and more normal coactivation between rostral-and-caudal trunk within the trunk motor cortex. However, caudal-only trunk representations remained different from intact.

\section{Trunk motor areas by dorsal-and-ventral (biomechanical) groupings}

For the two NTX spinalized groups, we next subdivided the segmental trunk area (i.e., midthoracic and low thoracic segmental representations) into dorsal and ventral trunk classifications (as dorsal-and-ventral coactive, ventral-only, and dorsal-only) and expressed the areas of these as percentages of nonfacial motor cortex. These comparisons likely relate to degree of dorsoventral stiffening and fractionations of trunk in the cortical controlled trunk actions. At the midthoracic trunk segmental level (Fig. 3D), there were no significant differences between the two NTX spinalized groups for dorsal-and-ventral coactive ( $p=0.9, t$ test), ventral-only ( $p=0.72, t$ test $)$, and dorsal-only ( $p=0.21, t$ test $)$ trunk. However, at the low thoracic trunk segmental level (Fig. $3 E)$, NTX-Robot rats had significantly larger representations of dorsal-and-ventral coactive $(p<0.018$, Wilcoxon's rank-sum test) and ventral-only ( $p<0.016, t$ test) muscle recruitment by ICMS, but no differences were found for the dorsal-only trunk representations ( $p=0.48$, Wilcoxon's rank-sum test), all compared with NTX-TM. Thus, robot training of NTX rats resulted in a significant expansion of low thoracic trunk representation that specifically included expansion of dorsal-and-ventral coactive and ventral-only representation at low thoracic levels.

\section{Effect of training on coactivation density of trunk motor representation}

To examine degree and richness of muscle synergy in representations at sites, we defined a "coactivation density" as the total number of trunk EMG channels coactivated (of a total possible 15) per spatial location in the trunk motor cortex. Total trunk coactivation density was found to be significantly larger for the NTX-Robot rats compared with the NTX-TM rats $(p<0.002, t$ test; Fig. 4A). Total coactivation density for the normal group was found to be $3.9 \pm 0.19$, and this was not significantly different from the NTX-Robot rats. Both these groups (normal and NTXRobot) were significantly larger in coactivation density compared with the NTX-TM group $\left(p<0.0001, F_{(2,21)}=20.84\right.$, one-way ANOVA with Bonferroni's-corrected post hoc comparisons). We next examined coactivation density for the two NTX spinalized groups analyzed by trunk segmental level. To calculate this, we only considered trunk motor sites in which a particular segmental representation was obtained (e.g., count all low-thoracic trunk EMG channels coactivated only when at least one low thoracic trunk EMG channel was active). This avoided possible bias in the treadmill-trained group, because NTX-TM rats only had $27.5 \pm$ $7 \%$ of trunk motor cortex representation for low thoracic trunk, whereas NTX-Robot rats had $80 \pm 4.2 \%$. Because one NTX-TM rat did not have any low thoracic representation, its low thoracic coactivation density was considered to be 0 . We did not find any significant differences in the coactivation density of midthoracic trunk representation between the two groups of NTX spinalized rats $(p=0.53, t$ test; Fig. $4 B$ ). In contrast, the coactivation density of low thoracic trunk representation was significantly higher in NTX-Robot rats compared with NTX-TM rats $(p<0.005$, Wilcoxon's rank-sum test; Fig. $4 B$ ). Low trunk appeared in richer or more complex synergies in NTX-Robot rats. Again, when we did multiple group comparisons, we found that coactivation density for low thoracic for normal rats $(1.8 \pm 0.16)$ was not significantly different from NTX-Robot rats, but we found that both these groups were significantly different from NTX-TM rats $(p=$ $0.001, F_{(2,21)}=9.69$, one-way ANOVA with Bonferroni'scorrected post hoc comparisons). Given that we found lumbar representations in only one NTX-TM rat and in three NTXRobot rats, we again did not make detailed statistical comparisons for lumbar trunk coactivation density.

We next examined the coactivation density sorted by dorsal and ventral trunk (Fig. 4C). Coactivation density for both dorsal and ventral trunk representation was significantly higher in NTX-Robot rats compared with NTX-TM rats ( $p<0.05, t$ test). Thus, robot training of NTX rats significantly increased the total coactivation density of trunk representation, and more specifi- 


\section{A Total Trunk Coactivation Density}

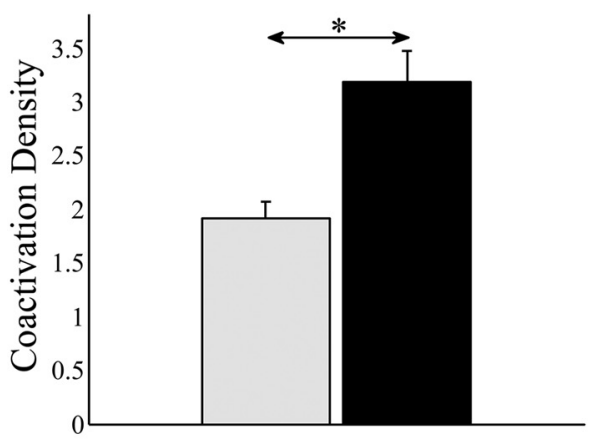

B Trunk Coactivation Density by Segmental level

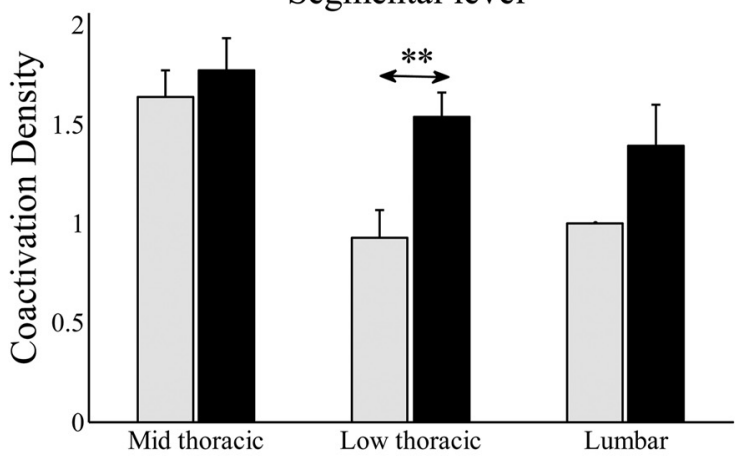

C Trunk Coactivation Density by Dorsal or Ventral aspect

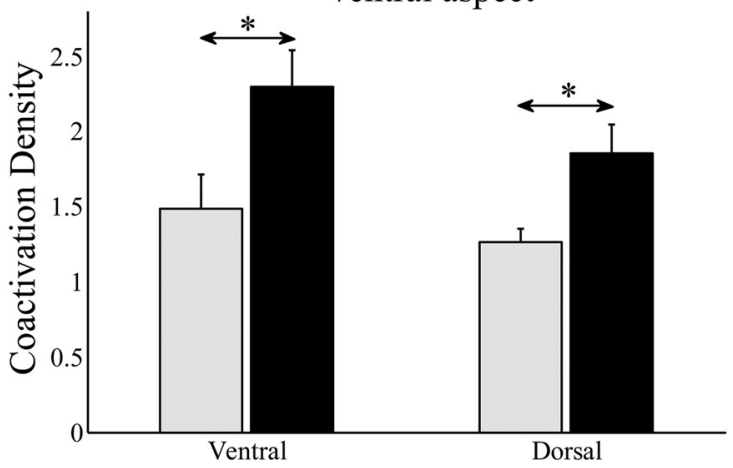

NTX - Treadmill

Figure 4. Trunk coactivation density comparisons. (Coactivation density is defined as the total number of trunk EMG recordings that were coactive at a spatial location in the trunk motor cortex.) $\boldsymbol{A}$, Total trunk coactivation density. The NTX-Robot group is significantly higher than the NTX-TM group. $\boldsymbol{B}$, Coactivation density sorted by trunk segmental location. The NTX-Robot group is significantly higher than the NTX-TM group for low thoracic coactivation density. $C$, Coactivation density by ventral and dorsal muscle targets. The NTX-Robot group is significantly higher than the NTX-TM group for both ventral and dorsal coactivation densities. ${ }^{*} p<0.05, t$ test; ${ }^{* *} p<0.05$, Wilcoxon's rank-sum test; data expressed as mean \pm SEM.

cally that for caudal (low thoracic) trunk, and for ventral and dorsal trunk. Muscle segments were coalesced more extensively into synergies across the cortex in the NTX-Robot rats.

Spatial locations of trunk motor representations

We next examined the spatial locations of trunk motor representations in the different groups of rats. As reported previously, in normal rats, the majority of trunk motor sites are located caudal to the bregma landmark and within $2-3 \mathrm{~mm}$ of the midline (medial $\leftrightarrow$ lateral; Fig. 2). Overlay of trunk motor maps from all NTX rats is shown in Figure 5 ( $A$, NTX-TM; $B$, NTX-Robot). We calculated the center of gravity (COG) of the total trunk motor representation [spatial average location $(x, y)$ of trunk motor sites] for each spinalized rat and compared this between the two NTX spinalized groups (Fig. 5C). There were no significant differences between the medial-and-lateral COG between the two spinalized groups ( $p=0.63, t$ test). However, NTX-Robot rats showed a significant shift in the caudal direction toward the normal topography (normal group mean rostral-and-caudal COG, $-0.55 \pm 0.3 \mathrm{~mm})$ compared with NTX-TM rats $(p<0.005$, Wilcoxon's rank-sum test). Additionally, there were no significant differences between the two spinalized groups for forelimb COG (medial-and-lateral, $p=0.93, t$ test; rostral-and-caudal, $p=0.76, t$ test; data not shown). Therefore, robot training of NTX rats caused a spatial shift in the caudal direction of trunk motor cortex representations (i.e., toward the normal topography).

We next divided trunk motor sites into cortical regions based on their locations relative to bregma: (1) above bregma and (2) at/below bregma (Fig. 6A). As reported above, total trunk motor sites in the two groups were not significantly different $(p=0.47$ NTX-TM was $15.1 \pm 2$ and NTX-Robot was $17.9 \pm 3.1$ ). Average trunk motor sites above bregma for NTX-Robot rats and NTX-TM rats were not significantly different between the two groups ( $p=0.6, t$ test). However, trunk motor sites at and below bregma were significantly higher for the NTX-Robot group ( $p<$ $0.03, t$ test). When we compared the NTX spinalized groups with normal rats for at/below bregma sites, there were no significant differences between the normal rats $(8.9 \pm 0.8$ sites $)$ and the NTX-Robot group, but again the NTX-TM group of rats was significantly different compared with both normal and NTXRobot rats $\left(p<0.004, F_{(2,21)}=7.32\right.$, one-way ANOVA with Bonferroni's-corrected post hoc comparisons). Therefore, robot training, but not the treadmill training alone, caused a more "normal" spatial pattern of trunk motor cortical representation.

For the two spinalized groups, we then further classified trunk motor sites as rostral- only, caudal- only, and rostral-and-caudal coactive as above by their relative location to bregma (Fig. $6 C, D$ ). For rostral-only trunk, at the region above bregma, the NTX-TM rat group site number was significantly higher than the NTXRobot group ( $p<0.003$, Wilcoxon's rank-sum test; Fig. $6 C$ ), whereas we found no significant differences for the rostral-only trunk in the region at/below bregma ( $p=0.2$, Wilcoxon's ranksum test; Fig. $6 D$ ). For caudal-only trunk, there were no significant differences in the region above bregma $(p=0.23$, Wilcoxon's rank-sum test; Fig. $6 C$ ), and, for the region at/below bregma, these were also not significant (although a higherpowered study might show differences; $p=0.08$, Wilcoxon's rank-sum test; Fig. $6 D$ ). For rostral-and-caudal coactive trunk, NTX-Robot rats had more motor sites above bregma, but again these did not differ significantly from NTX-TM rats $(p=0.14, t$ test; Fig. $6 C$ ). However, NTX-Robot rats did have significantly more rostral-and-caudal coactive motor sites in the at/below bregma region $(p<0.001$, Wilcoxon's rank-sum test; Fig. $6 D)$ compared with NTX-TM rats.

We next examined the coactivation density for the trunk motor representations in the two cortical regions (Fig. 6B). No significant differences were found between the two spinalized groups for trunk coactivation density in the region above bregma ( $p=0.29, t$ test). However the NTX-Robot group had significantly larger coactivation density in the region at/below bregma ( $p<0.001, t$ test). Thus, robot training of NTX rats resulted in significant reorganization (increase 


\section{A Overlay of Trunk Motor Maps for all NTX Treadmill trained rats}

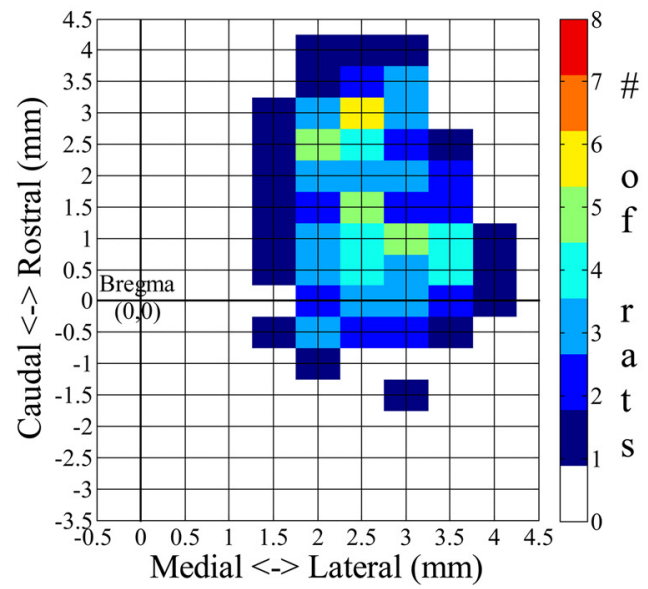

C Center of Gravity for Trunk Motor Representations in each NTX rat

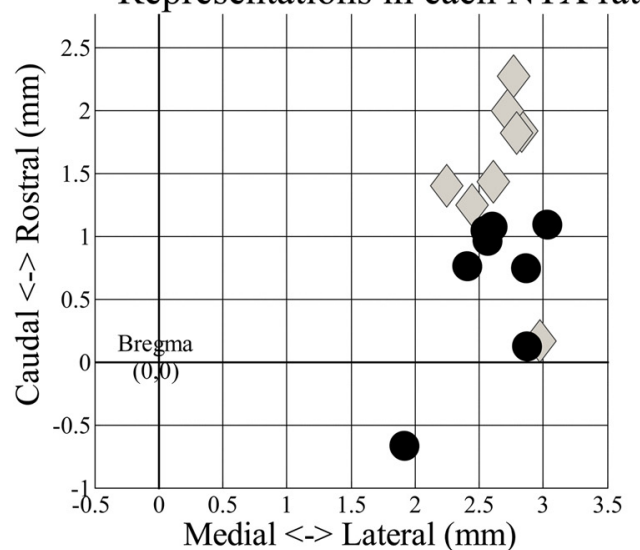

B Overlay of Trunk Motor Maps for all NTX Robot trained rats

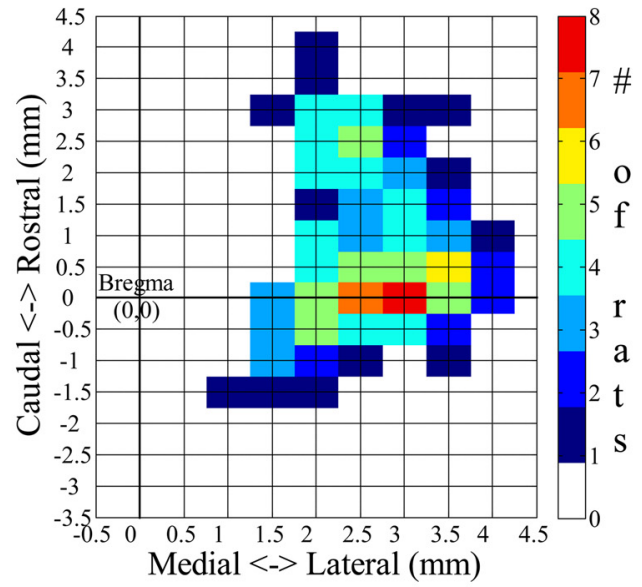

D Average Center of Gravity for Trunk Motor Representations

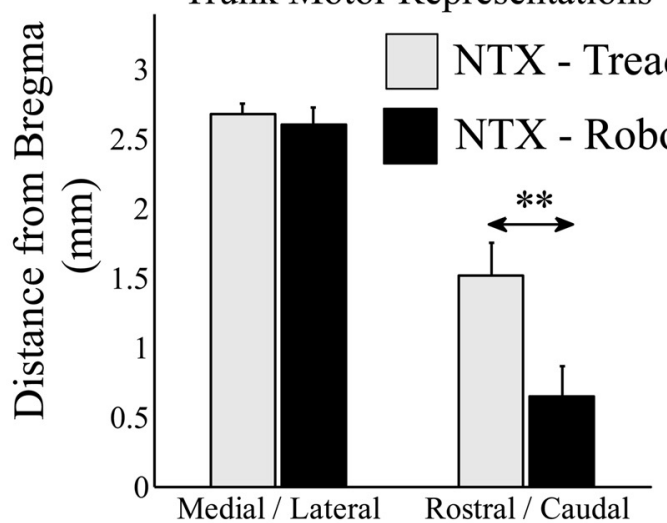

Figure 5. Overlay of trunk motor maps in adult NTX-TM rats $(n=8)$ or NTX-Robot rats $(n=8)$. Color shades indicate the number of rats with trunk motor representation at a particular spatial (stereotactic) location in the cortex. Motor representations were obtained at $60-80 \mu \mathrm{A}$ currents. Rostral is at the top of the map, and bregma is at $(0,0)$. Numbers on the axis represents distance in millimeters. For comparison purposes, all maps are presented as the right cortex in the same orientation. C, Scatter plots showing COG (spatial average location: medial-and-lateral and rostral-and-caudal of trunk motor cortex sites) calculated for each NTX rat. Note that the rostral-and-caudal scale here differs from that in $\boldsymbol{A}$ and $\boldsymbol{B}$, adjusted as a result of reduced range of COG. $\boldsymbol{D}$, Average COG calculated for both spinalized groups. The NTX-Robot group COG is significantly different (more caudal) from the NTX-TM group for rostral-and-caudal COG. ** $p<0.05$, Wilcoxon's rank-sum test; data expressed as mean \pm SEM.

in coactivation density and rostral-and-caudal coactivation) in the cortex region at/below bregma (which was returning toward normal topography).

\section{Functional coupling between the trunk and forelimb}

We examined motor map overlap between trunk and forelimb motor representations. These overlaps might be related to interlimb/trunk coordination for locomotion. To examine overlap, we divided trunk motor sites in each rat into three categories: (1) sites in which the trunk overlaps with the hindlimb; (2) sites in which the trunk overlaps with the forelimb; and (3) sites in which the trunk does not overlap with either limb. We expressed these as a percentage of the total trunk motor representation (Fig. 7A). As already stated, and not surprisingly, none of the spinalized rats had hindlimb representations. As shown previously, there was a significant amount of trunk motor representation overlap with hindlimb representation in normal rats, and, after adult SCI, significant overlap is reported between the trunk and forelimb (Oza and Giszter, 2014).With robot training in NTX rats, we observed a significant decrease in the map overlap between the trunk and forelimb in the NTX-Robot rats and consequently an increase in trunk representation without any limb overlap compared with NTX-TM rats $(p<0.05, t$ test; Fig. $7 A)$. Because we observed this increased decoupling of trunk and forelimb representation with robot training while overall coactivation patterns increased as reported above, we next calculated trunk coactivation density for trunk motor representations that overlapped with forelimb and density for trunk motor representations without any forelimb overlap (Fig. $7 B$ ). Trunk coactivation density was significantly higher both when the trunk and forelimb overlapped $(p=0.04, t$ test) and for the trunk only ( $p<0.0003, t$ test) for NTX-Robot rats compared with NTX-TM rats. Although coactivation densities for both types of sites in the cortex were significantly larger for the NTX-Robot rats than NTX-TM rats, the magnitude of change in coactivation density in which the trunk did not overlap with the forelimb was the highest.

The total number of forelimb motor sites (including trunk overlap) was not significantly different between the two spinalized groups (29.4 \pm 2.8 for NTX-TM and $27.4 \pm 2.5$ for NTXRobot rats, $p=0.6, t$ test). However, if we normalized forelimb 
A Total Trunk Motor sites relative to bregma

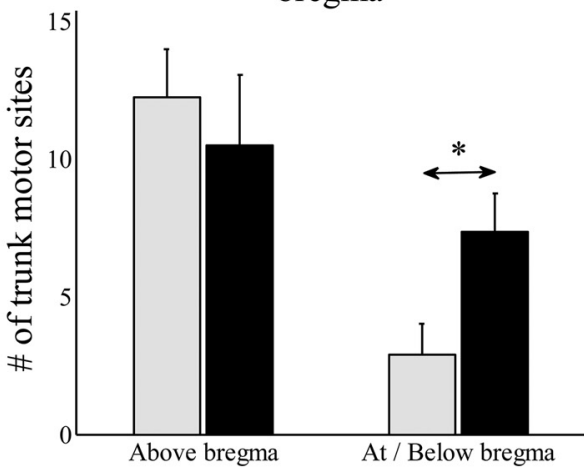

C Rostral-Caudal Trunk overlap in Cortex - Above bregma

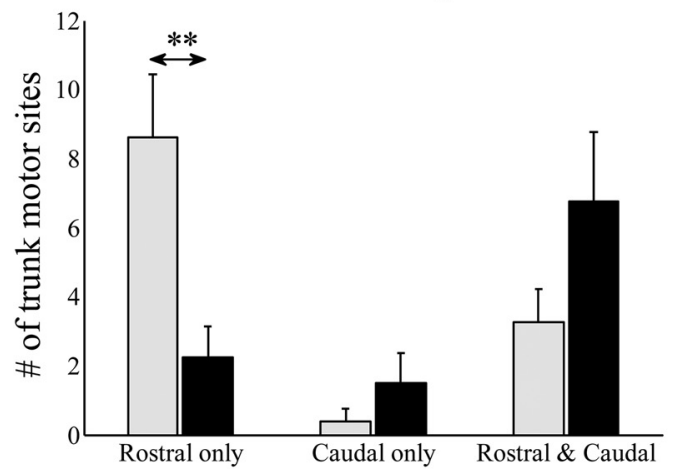

B Total Trunk Coactivation Density relative to bregma

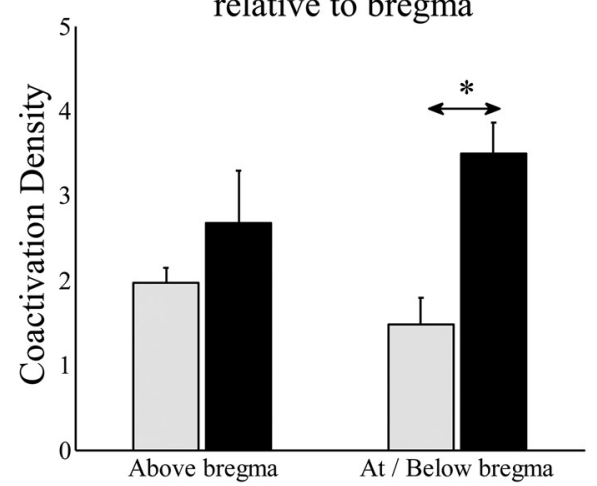

NTX - Treadmill NTX - Robot
D Rostral-Caudal Trunk overlap in Cortex - At / Below bregma

Figure 6. Trunk motor cortex representations feature variations relative to bregma. $\boldsymbol{A}$, Total trunk motor sites classified based on their relative location to bregma. The NTX-Robot group had a significantly larger number of trunk motor sites at/below bregma. $B$, Coactivation density calculated for trunk motor sites above bregma and at/below bregma. The NTX-Robot group is significantly different for coactivation density at/below bregma. C, D, Trunk motor representations sorted by segmental level overlap: (1) rostral (midthoracic) only; (2) caudal (low thoracic and/or lumbar) only; and (3) rostral-and-caudal coactive. We here compare these after sites are spatially classified based on their relative location to bregma: $\boldsymbol{C}$, above bregma; $\boldsymbol{D}$, at/below bregma. $\boldsymbol{C}$, The NTX-TM group has significantly higher trunk motor sites for rostral-only trunk above bregma. $\boldsymbol{D}$, The NTX-Robot group has significantly higher rostral-and-caudal coactive sites at/below bregma. ${ }^{*} p<0.05, t$ test; ${ }^{* *} p<0.05$, Wilcoxon's rank-sum test; data expressed as mean \pm SEM.

motor area to the size of the nonfacial motor cortex, we found the normalized forelimb motor area to be slightly but significantly higher in NTX-TM rats compared with NTX-Robot rats $(p=$ $0.041, t$ test; data not shown).

Effect of training on richness of trunk motor representation To examine the varieties of muscle synergy represented in the cortex, we used entropy- and mutual information-based measures. Higher entropy in motor maps effectively indicates more types of synergy. We use the term richness here as a shorthand to convey higher entropy measures associated with trunk representations in the binary motor maps that we generated. Mutual information among sites measures the degree of correlation and consistency in synergy representation taken as a whole. We examined these measures of richness and consistency of cortical representations in the following ways.

(1) We calculated cumulative entropies for all trunk EMG channels per rat (sum of entropies for all 15 trunk EMG channels) as described in Materials and Methods (Eq. 1) and averaged these across all rats in a group (Fig. 8A). NTX-Robot rats had a significantly larger cumulative trunk entropy than the NTX-TM rats $(p<0.02, t$ test $)$, indicating an increased richness of representations. We then calculated and compared cumulative entropy for trunk EMG channels organized by muscle segmental level (Fig. $8 B)$. For example, cumulative entropy for midthoracic levels was taken as the sum of entropies for all five midthoracic trunk channels. We found that the NTX-Robot rats had significantly larger cumulative trunk entropy than the NTX-TM rats for sites representing low thoracic muscles ( $p<0.001, t$ test) but not for sites representing midthoracic muscles $(p=0.9, t$ test) level. Richness of representation was significantly increased in caudal trunk controls in NTX-Robot rats.

We also calculated the cumulative entropies for all spatial locations in the cortex. We then sorted sites into two areas by their relative location to bregma (above, at/below bregma; Fig. $8 \mathrm{C}$ ). The area entropy measure of the spatial variations in entropy over the motor map (or spatial variations in richness of representation) was not significantly different between the NTX-Robot and NTX-TM groups for sites above bregma ( $p=0.98, t$ test). However, the NTX-Robot group had significantly larger cortex site entropy in the area of at/below bregma locations compared with the NTX-TM group ( $p<0.007$, Wilcoxon's rank-sum test). Therefore, robot training of NTX rats significantly increased the richness of trunk representations (cumulative entropy) overall. This increased specifically for the low thoracic segments, and spatially in the cortex, the motor richness was increased significantly in the at/below bregma locations.

(2) Mutual information measures on the map data capture how similarly or consistently trunk muscle segments were 


\section{A Percent of Trunk Motor Cortex overlap with Forelimb Motor representations}
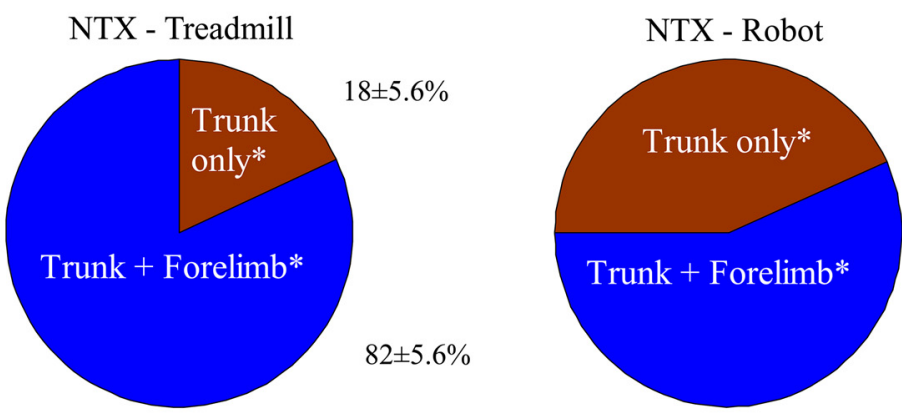

B Trunk Coactivation density with or without forelimb motor overlap

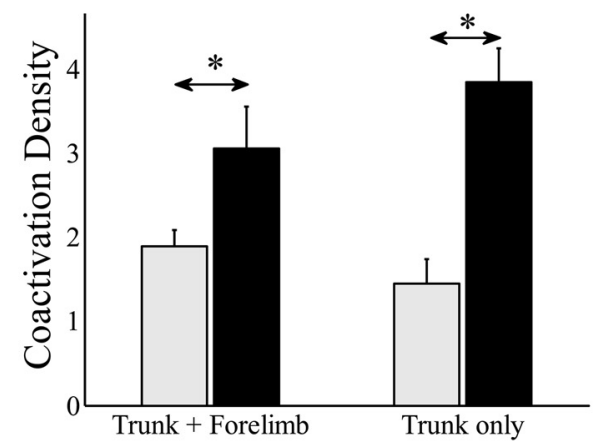

Figure 7. A, Trunk motor cortex sites classified based on map overlaps as trunk overlap with forelimb, trunk overlap with hindlimb, and trunk without any limb overlap and expressed as percentage of total trunk. None of the spinalized rats had hindlimb representation. The NTX-TM group has a significantly larger percentage of trunk motor representation that overlaps with the forelimb. The robot group has a significantly larger percentage of trunk representation activated alone (without any forelimb coactive). $\boldsymbol{B}$, Trunk coactivation density calculated for trunk representation that overlaps with the forelimb and without any forelimb coactive. The NTX-Robot group has significantly larger coactivation density for both representations. ${ }^{*} p<0.05, t$ test; data expressed as mean \pm SEM.

grouped and coalesced among sites. We examined the mutual information between different trunk EMG channels in each rat as described in Materials and Methods (Eq. 2; Fig. 9A). These values ranged from 0 to 1 bit, and varied among channels and rats, as can be seen clearly in Figure 9A. However, in NTX-Robot rats, they were more often higher. We summed mutual information measures over the unique (lower half matrix) muscle pairings and averaged these across all rats in a group for cumulative measure (Fig. 9B). NTX-Robot rats had significantly higher cumulative mutual information than the NTX-TM rats ( $p<0.05, t$ test). In effect, the NTX-Robot rats had richer synergies (higher entropy) that were also represented more consistently (higher mutual information). However, because there was significantly higher richness (cumulative entropy) in NTX-Robot rats, it was conceivable that this fact alone accounted for the higher apparent consistency in the mutual information measures. To test whether the consistency difference between NTX-Robot and NTX-TM rats was more than this effect, we next calculated and compared the so-called coefficient of constraint (or uncertainty coefficient; Press et al. 2007), which could also be termed "normalized mutual information" (as described in Materials and Methods, Eqs. 3 and 4). NTX-Robot rats also had significantly higher normalized cumulative mutual information than the NTX-TM rats $(p<$ $0.05, t$ test; Fig. 9C). In essence, this final calculation confirmed that both a richer and a more consistent mapping of muscle synergies occurred in the cortex after robot training, mirroring
$43.3 \pm 7.4 \%$

the increased function and motor skill levels that the NTX-Robot rats achieved.

\section{Discussion}

We examined changes in trunk motor cortex representations after robot rehabilitation of adult rats spinalized as neonates (NTX rats), comparing motor maps and muscle groupings within maps. Motor topography changes may follow skill development, but appropriate muscle use is a necessary prerequisite and component of skill (Nudo et al., 1996b; Kleim et al., 1998; Plautz et al., 2000). Robot rehabilitation improved function and induced significant reorganization in both muscle patterns recruited and maps in motor cortex. These were not observed in the treadmill therapy with no functional improvement. Changes included the following: (1) expansion of motor area representing the caudal trunk; (2) increase in some patterns of trunk coactivation at cortex sites; (3) increased richness of trunk cortex motor representations; (4) displacement of trunk motor representations in the cortex toward more normal topography; and (5) somatotopic segregation of the trunk and forelimb motor representations that plasticity and compensations after SCI had caused to overlap.

\section{Effect of robot training on trunk motor area}

Robot-trained NTX rats' total trunk motor area resembled control (treadmillonly) NTX rats, perhaps unsurprisingly. Skill learning usually correlates with altered representations within conserved global topographies in the motor cortex. For example, skilled reach-trained rats expanded wrist and digit representation and decreased elbow/ shoulder representation within the caudal forelimb area without altering the total area (Kleim et al., 1998). Similarly, we saw rearrangements of trunk representations within trunk motor cortex. Robot-trained rats increased separation of forelimb and trunk representations. Robot training significantly increased representation of low thoracic (caudal) trunk. The dorsal-and-ventral overlap and ventral-only representation of low thoracic muscles also increased compared with treadmill trained. The map area and overlap of rostral-and-caudal trunk increased.

We speculate that NTX-Robot rats learned to effectively enrich trunk representations and recruit caudal trunk during weight-supporting steps. Caudal trunk muscle activity is influenced by hindlimb afferents (Wada et al., 1999, 2000, 2003; Wada and Kanda, 2001) and thus by hindlimb weight support (Zomlefer et al., 1984). Trunk muscles are mechanically coupled and possess broad multisegmental reflexes. Reflex pathways between trunk muscles and central pattern generation (CPG) and hindlimb controls (Udoekwere, 2010) could provide bidirectional information and force conduits in NTX rats and particularly through caudal trunk muscles. In addition, after complete SCI in cats, spinal motoneurons start to regain intrinsic excitability (Murray et al., 2010), but their synaptic inputs are altered 
A Cumulative Entropy for total Trunk Motor representations

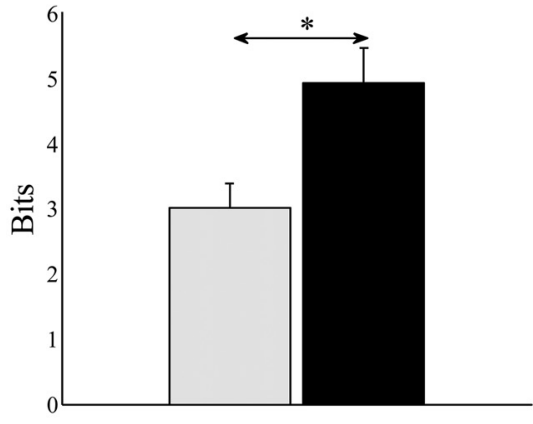

B Cumulative Entropy for Trunk Motor representations by Segmental level

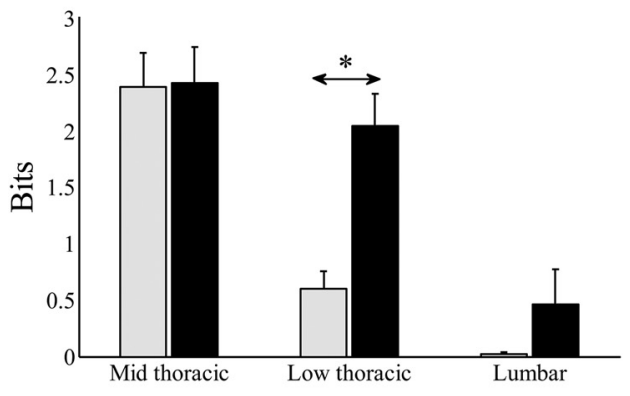

C Cumulative Entropy for Trunk Motor representations across stimulation sites relative to bregma

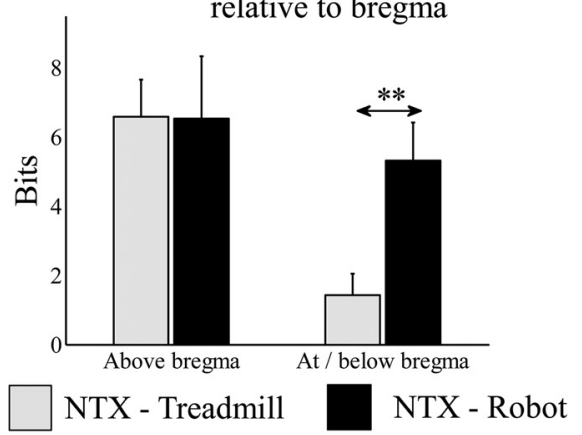

Figure 8. A, Cumulative entropy in the trunk motor cortex for all trunk EMG recording sites calculated for each rat and averaged across rats per group. This measures richness of representations. The NTX-Robot group mean cumulative entropy is significantly larger than the NTX-TM group. $\boldsymbol{B}$, Cumulative entropy in the trunk motor cortex compared by segmental level of EMG recording sites (midthoracic, low thoracic, and lumbar). The NTX-Robot group entropy is significantly larger than the NTX-TM group entropy for the low thoracic level. C, Cumulative cortex site entropy with respect to bregma location. The NTX-Robot group cumulative cortex site entropy is significantly larger than that of the NTX-TM group for at/below bregma locations. NTX-Robot rats have richer representations of muscles across their representations. ${ }^{*} p<0.05, t$ test; ${ }^{* *} p<0.05$, Wilcoxon's rank-sum test; data expressed as mean \pm SEM.

(Johnson et al., 2013), raising the possibility for enhanced trunk coordination to facilitate locomotor behavior after SCI. Hindlimb stepping cues (transmitted through caudal trunk and limb interactions to the rostral trunk) might thus reach sensorimotor cortex and provide feedback for cortical motor loops driving the rostral-and-caudal trunk. Such enhanced cortical control loops to trunk could support balance and generate taskdependent trunk motions, reframing crude stepping motions into balanced weight-supporting steps (U. I. Udoekwere, C. S. Oza, and S. F. Giszter, unpublished observations). Twenty percent of NTX rats can autonomously weight support (i.e., devel- oped skills around weaning, unlike rats here) and without exception possess cortical motor representations of the caudal trunk (Giszter et al., 1998). Cortical trunk controls may be crucial for these rats' hindlimb weight support (Giszter et al., 2007, 2008a,b). However, active spinal CPG circuitry is still the necessary basis for such rats to step.

\section{Effect of robot training on cortical motor synergies}

Motor cortex representations may include complex synergies within their topography. The motor cortex likely controls muscles and movements in an integrated manner (Schieber, 2001; Capaday et al., 2013). Such integrated control might select cortical motor synergies matched to biomechanical constraints and task demands (Kargo and Nitz, 2003; d'Avella and Bizzi, 2005; Tresch and Jarc, 2009). The primary motor cortex likely orchestrates such cortical muscle synergies (Holdefer and Miller, 2002) together with simpler motor modules residing in the spinal cord (Tresch et al., 2002; Hart and Giszter, 2010; Giszter and Hart, 2013). Learning or injury can alter the expression of such motor synergies (Cheung et al., 2012). Cortical (Overduin et al., 2012) or spinal (Bizzi et al., 1991; Giszter et al., 1993) electrical stimulation can reveal these synergies, and evoked patterns may often match those observed during natural behavior (Kargo and Giszter, 2000; Graziano et al., 2002; Griffin et al., 2011, 2014; Overduin et al., 2012, 2014).

We explored cortical synergies and their richness using map area overlaps, trunk coactivation measures, entropy (measuring overall richness of spatial representation of synergies), and mutual information (measuring degree of consistency of synergies). Normal rats' motor maps show overlapping trunk and hindlimb in the caudal cortex, with small overlaps for the trunk and forelimb in the rostral cortex (Donoghue and Wise, 1982; Neafsey et al., 1986; Oza and Giszter, 2014). All NTX rats instead showed large map overlap for the trunk and forelimb. However, robot training significantly reduced this trunk-forelimb overlap and increased trunk-only representations, i.e., partly fractionated these. Overlap of trunk and forelimb (resembling "merging"; Cheung et al. 2012) after neonatal SCI and treadmill training without weight support matches maps in chronic adult spinal cord-injured rats (Oza and Giszter, 2014). Such overlaps in paraplegic SCI rats may be adaptive as a result of altered task demands and plant biomechanics associated with their paraplegia. Such compensatory merging or superposition of cortical map representations attributable to co-contraction have also been shown with motor learning or increased use (Liepert et al., 1999; Tyc et al., 2005; Tyč and Boyadjian, 2011). Previous work (Ramanathan et al., 2006) showed that rehabilitation training in rats after brain injury restored complex motor representations otherwise lost, and this reorganization correlated significantly with the degree of recovery of function. During robot training, application of elastic forces at the pelvis in NTX rats allowed (and aided) hindlimb weight support, and altered task demands and the trunk biomechanical framework for robot-trained rats. The robot training likely increased biomechanical options for trunk and forelimb within the target (locomotion) task (see Schweighofer et al., 2012 for discussion), thereby allowing fractionating of trunk-forelimb synergies and somatotopic segregation of trunk and forelimb motor map representations. Synergies were enriched, with some concomitant consistencies developing, based on the information measures. These observed changes were accompanied by caudal shifts (away from forelimb representations) of trunk motor representations, more resembling normal topography. Therefore, robot rehabilitation reorganized the adaptive and compensatory plasticity that followed complete SCI. 
A Mutual Information among recording sites for Trunk Motor representations in each rat

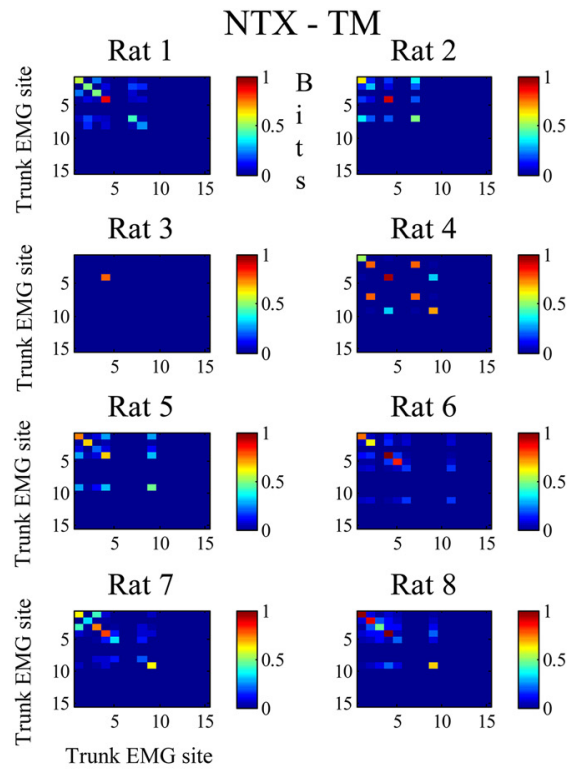

B Cumulative Pairwise Mutual Information for Trunk Motor

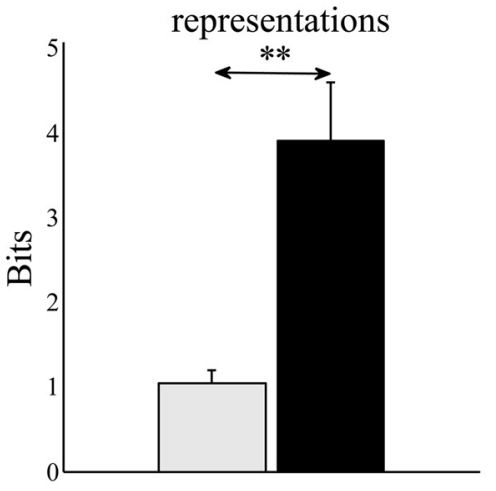

C Normalized Cumulative Pairwise Mutual Information for Trunk Motor representations

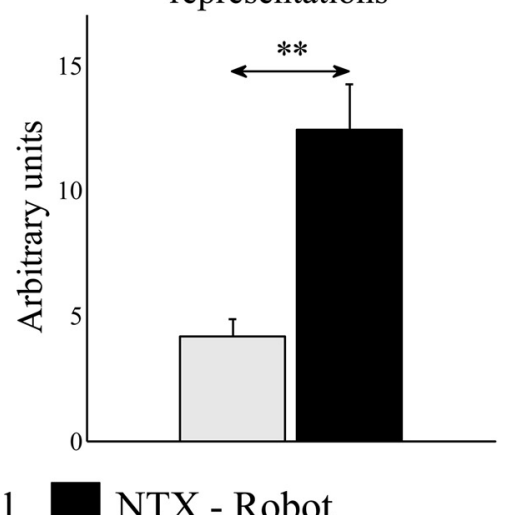

NTX - Treadmill

Figure 9. $\quad A$, Recruited trunk segments patterns of mutual information in each rat in the NTX-TM and NTX-Robot groups. The mutual information ranges from 0 to 1 bit and varies among rats, sites, and treatments. It measures degree of consistency among sites. $\boldsymbol{B}$, Cumulative mutual information in each rat, averaged for all rats in a group. The NTX-Robot group mutual information is significantly higher than the NTX-TM group. C, Normalized cumulative mutual information (i.e., coefficient of constraint) is significantly higher for the NTX-Robot group compared with the NTX-TM group. NTX-Robot rats are more consistent across their representations. ${ }^{* *} p<0.05$, Wilcoxon's rank-sum test; data expressed as mean \pm SEM.

Novel synergistic recruitment of trunk muscles and segments in the motor cortex accompanied robot training of NTX rats. Overlap between the rostral-and-caudal trunk increased. To measure increasing richness, we used coactivation density measures. Coactivation density captures the muscle number recruited at sites, i.e., the degree of divergence of output from a cortex site to different trunk muscles/segments. In contrast, cumulative entropy and mutual information captured the enhanced richness and variety of synergistic recruitment of different trunk muscles and segments at different cortex sites. Both of these measures increased. Increasing richness of trunk representations matched the expanded trunk motor repertoire and function of the NTX rats that were trained on a robot. Likely, the richer cortical trunk motor representations provided ready access to different combinations of trunk segments and enhanced the range of coordinated trunk motions possible, and thereby postural stability, and weight support. This matches the idea that motor skill involves optimal feedback selection and control of complex muscle synergies from a large pool of potential synergies (Kargo and Nitz, 2003; Todorov, 2004; Todorov et al., 2005; Scott, 2012). Additionally, it qualitatively resembles cortical plasticity associated with skill learning (Kleim et al., 1998), rehabilitation training-induced plasticity after stroke (Nudo et al., 1996a; Nishibe et al., 2014) and incomplete SCI (Winchester et al., 2005; Knikou, 2012).

Location of trunk motor representation In normal rats, most trunk motor representation overlaps with hindlimb motor representation in the caudal (postbregma) sensorimotor overlap region of the cortex. There is also a small motor region of the upper trunk in the rostral (prebregma) cortex. The caudal trunk area is deafferented after complete SCI. Sensory motor overlap is more vulnerable to silencing (Hummelsheim and Wiesendanger, 1985). Like adult SCI rats (Oza and Giszter, 2014), NTX rats had larger trunk motor representations in the rostral cortex and significant trunk and forelimb overlap. With non-stepping rehabilitation training in adult SCI rats, trunk motor representations were displaced more rostrally. After improving function with robot training, NTX rats' trunk motor representations were displaced caudally (toward the deafferented cortex and normal rats' topography). Trunk motor sites at and below the bregma line increased significantly in NTX-Robot rats compared with NTX-TM rats. Additionally, trunk coactivation density, rostral-andcaudal trunk overlap, and the richness of synergies were all significantly higher at and below bregma in NTX-Robot rats. These plastic changes at/below bregma suggest reallocation of specific trunk cortical motor resources during functional robot rehabilitation. Sensory plasticity is seen in deafferented cortex after treadmill training in NTX rats (Kao et al., 2009, 2011) and after passive bike exercise in adult SCI rats (Graziano et al., 2013). The emergent trunk motor representations in NTX deafferented cortex here may be critical for the functional recovery with robot support observed here (Giszter et al., 2008a). Lesioning this area in NTX rats before robot training would demonstrate this.

The various results in the neonatal spinal injury model may in part speak to the kinds of possibilities after pediatric injury in the clinic (Fox et al., 2010, 2013). However, for the reasons we have noted, extending these data to adult injury requires an understanding of whether similar plasticity and representations are 
available after adult SCI and how best to promote them. This must remain for future work.

In summary, our study shows that successful robot rehabilitation training of adult rats spinalized as neonates induces reorganization of the trunk motor cortex. The reorganization reverses some deviations from normal patterns seen in the cortex of NTX rats, including changes that also occur in adult SCI rats. In addition, an alteration and increased richness of synergies that may relate to neurorecovery and skill acquisition occurs in the maps.

\section{References}

Antri M, Orsal D, Barthe JY (2002) Locomotor recovery in the chronic spinal rat: effects of long-term treatment with a 5-HT2 agonist. Eur J Neurosci 16:467-476. CrossRef Medline

Basso DM, Beattie MS, Bresnahan JC (1995) A sensitive and reliable locomotor rating scale for open field testing in rats. J Neurotrauma 12:1-21. CrossRef Medline

Bizzi E, Mussa-Ivaldi FA, Giszter S (1991) Computations underlying the execution of movement: a biological perspective. Science 253:287-291. CrossRef Medline

Bjerkefors A, Carpenter MG, Cresswell AG, Thorstensson A (2009) Trunk muscle activation in a person with clinically complete thoracic spinal cord injury. J Rehabil Med 41:390-392. CrossRef Medline

Capaday C, Ethier C, Van Vreeswijk C, Darling WG (2013) On the functional organization and operational principles of the motor cortex. Front Neural Circuits 7:66. CrossRef Medline

Cha J, Heng C, Reinkensmeyer DJ, Roy RR, Edgerton VR, De Leon RD (2007) Locomotor ability in spinal rats is dependent on the amount of activity imposed on the hindlimbs during treadmill training. J Neurotrauma 24:1000-1012. CrossRef Medline

Cheung VC, Turolla A, Agostini M, Silvoni S, Bennis C, Kasi P, Paganoni S, Bonato P, Bizzi E (2012) Muscle synergy patterns as physiological markers of motor cortical damage. Proc Natl Acad Sci U S A 109:14652-14656. CrossRef Medline

Cohen LG, Bandinelli S, Findley TW, Hallett M (1991) Motor reorganization after upper limb amputation in man. A study with focal magnetic stimulation. Brain 114:615-627. CrossRef Medline

Cover TM, Thomas JA (2006) Elements of information theory, Ed 2. Hoboken, NJ: Wiley Interscience.

d'Avella A, Bizzi E (2005) Shared and specific muscle synergies in natural motor behaviors. Proc Natl Acad Sci U S A 102:3076-3081. CrossRef Medline

de Leon RD, Reinkensmeyer DJ, Timoszyk WK, London NJ, Roy RR, Edgerton VR (2002) Use of robotics in assessing the adaptive capacity of the rat lumbar spinal cord. Prog Brain Res 137:141-149. CrossRef Medline

Desroches G, Gagnon D, Nadeau S, Popovic MR (2013) Effects of sensorimotor trunk impairments on trunk and upper limb joint kinematics and kinetics during sitting pivot transfers in individuals with a spinal cord injury. Clin Biomech (Bristol, Avon) 28:1-9. CrossRef Medline

Dobkin BH, Apple D, Barbeau H, Basso M, Behrman A, Deforge D, Ditunno J, Dudley G, Elashoff R, Fugate L, Harkema S, Saulino M, Scott M (2003) Methods for a randomized trial of weight-supported treadmill training versus conventional training for walking during inpatient rehabilitation after incomplete traumatic spinal cord injury. Neurorehabil Neural Repair 17:153-167. CrossRef Medline

Dominici N, Keller U, Vallery H, Friedli L, van den Brand R, Starkey ML, Musienko P, Riener R, Courtine G (2012) Versatile robotic interface to evaluate, enable and train locomotion and balance after neuromotor disorders. Nat Med 18:1142-1147. CrossRef Medline

Donoghue JP, Wise SP (1982) The motor cortex of the rat: cytoarchitecture and microstimulation mapping. J Comp Neurol 212:76-88. CrossRef Medline

Fox EJ, Tester NJ, Phadke CP, Nair PM, Senesac CR, Howland DR, Behrman AL (2010) Ongoing walking recovery 2 years after locomotor training in a child with severe incomplete spinal cord injury. Phys Ther 90:793-802. CrossRef Medline

Fox EJ, Tester NJ, Kautz SA, Howland DR, Clark DJ, Garvan C, Behrman AL (2013) Modular control of varied locomotor tasks in children with incomplete spinal cord injuries. J Neurophysiol 110:1415-1425. CrossRef Medline

Frost SB, Iliakova M, Dunham C, Barbay S, Arnold P, Nudo RJ (2013) Reliability in the location of hindlimb motor representations in Fischer-344 rats: laboratory investigation. J Neurosurg Spine 19:248-255. CrossRef Medline

Ghosh A, Haiss F, Sydekum E, Schneider R, Gullo M, Wyss MT, Mueggler T,
Baltes C, Rudin M, Weber B, Schwab ME (2010) Rewiring of hindlimb corticospinal neurons after spinal cord injury. Nat Neurosci 13:97-104. CrossRef Medline

Giszter SF, Hart CB (2013) Motor primitives and synergies in the spinal cord and after injury-the current state of play. Ann N Y Acad Sci 1279: 114-126. CrossRef Medline

Giszter SF, Mussa-Ivaldi FA, Bizzi E (1993) Convergent force fields organized in the frog's spinal cord. J Neurosci 13:467-491. Medline

Giszter SF, Kargo WJ, Davies M, Shibayama M (1998) Fetal transplants rescue axial muscle representations in M1 cortex of neonatally transected rats that develop weight support. J Neurophysiol 80:3021-3030. Medline

Giszter SF, Davies MR, Graziani V (2007) Motor strategies used by rats spinalized at birth to maintain stance in response to imposed perturbations. J Neurophysiol 97:2663-2675. CrossRef Medline

Giszter S, Davies MR, Ramakrishnan A, Udoekwere UI, Kargo WJ (2008a) Trunk sensorimotor cortex is essential for autonomous weight-supported locomotion in adult rats spinalized as P1/P2 neonates. J Neurophysiol 100:839-851. CrossRef Medline

Giszter SF, Davies MR, Graziani V (2008b) Coordination strategies for limb forces during weight-bearing locomotion in normal rats, and in rats spinalized as neonates. Exp Brain Res 190:53-69. CrossRef Medline

Giszter SF, Hockensmith G, Ramakrishnan A, Udoekwere UI (2010) How spinalized rats can walk: biomechanics, cortex, and hindlimb muscle scalingimplications for rehabilitation. Ann N Y Acad Sci 1198:279-293. CrossRef Medline

Graziano A, Foffani G, Knudsen EB, Shumsky J, Moxon KA (2013) Passive exercise of the hind limbs after complete thoracic transection of the spinal cord promotes cortical reorganization. PLoS One 8:e54350. CrossRef Medline

Graziano MS, Taylor CS, Moore T (2002) Complex movements evoked by microstimulation of precentral cortex. Neuron 34:841-851. CrossRef Medline

Griffin DM, Hudson HM, Belhaj-Saï A, Cheney PD (2011) Hijacking cortical motor output with repetitive microstimulation. J Neurosci 31: 13088-13096. CrossRef Medline

Griffin DM, Hudson HM, Belhaj-Saif A, Cheney PD (2014) EMG activation patterns associated with high frequency, long-duration intracortical microstimulation of primary motor cortex. J Neurosci 34:1647-1656. CrossRef Medline

Harrison TC, Silasi G, Boyd JD, Murphy TH (2013) Displacement of sensory maps and disorganization of motor cortex after targeted stroke in mice. Stroke 44:2300-2306. CrossRef Medline

Hart CB, Giszter SF (2010) A neural basis for motor primitives in the spinal cord. J Neurosci 30:1322-1336. CrossRef Medline

Hidler J, Sainburg R (2011) Role of robotics in neurorehabilitation. Top Spinal Cord Inj Rehabil 17:42-49. CrossRef Medline

Holdefer RN, Miller LE (2002) Primary motor cortical neurons encode functional muscle synergies. Exp Brain Res 146:233-243. CrossRef Medline

Hsieh FH, Giszter SF (2011) Robot-driven spinal epidural stimulation compared with conventional stimulation in adult spinalized rats. Conf Proc IEEE Eng Med Biol Soc 2011:5807-5810. CrossRef Medline

Hummelsheim H, Wiesendanger M (1985) Is the hindlimb representation of the rat's cortex a "sensorimotor amalgam"? Brain Res 346:75-81. CrossRef Medline

Hussain S, Xie SQ, Liu G (2011) Robot assisted treadmill training: mechanisms and training strategies. Med Eng Phys 33:527-533. CrossRef Medline

Jain N, Catania KC, Kaas JH (1997) Deactivation and reactivation of somatosensory cortex after dorsal spinal cord injury. Nature 386:495-498. CrossRef Medline

Johnson MD, Kajtaz E, Cain CM, Heckman CJ (2013) Motoneuron intrinsic properties, but not their receptive fields, recover in chronic spinal injury. J Neurosci 33:18806-18813. CrossRef Medline

Kao T, Shumsky JS, Murray M, Moxon KA (2009) Exercise induces cortical plasticity after neonatal spinal cord injury in the rat. J Neurosci 29:7549 7557. CrossRef Medline

Kao T, Shumsky JS, Knudsen EB, Murray M, Moxon KA (2011) Functional role of exercise-induced cortical organization of sensorimotor cortex after spinal transection. J Neurophysiol 106:2662-2674. CrossRef Medline

Kargo WJ, Giszter SF (2000) Rapid correction of aimed movements by summation of force-field primitives. J Neurosci 20:409-426. Medline

Kargo WJ, Nitz DA (2003) Early skill learning is expressed through selection and tuning of cortically represented muscle synergies. J Neurosci 23: 11255-11269. Medline

Kleim JA, Barbay S, Nudo RJ (1998) Functional reorganization of the rat 
motor cortex following motor skill learning. J Neurophysiol 80:33213325. Medline

Knikou M (2012) Plasticity of corticospinal neural control after locomotor training in human spinal cord injury. Neural Plast 2012:254948. CrossRef Medline

Liepert J, Terborg C, Weiller C (1999) Motor plasticity induced by synchronized thumb and foot movements. Exp Brain Res 125:435-439. CrossRef Medline

MacKay DJC (2003) Information theory, inference, and learning algorithms, Ed 4. New York: Cambridge UP.

Miya D, Giszter S, Mori F, Adipudi V, Tessler A, Murray M (1997) Fetal transplants alter the development of function after spinal cord transection in newborn rats. J Neurosci 17:4856-4872. Medline

Moxon KA, Oliviero A, Aguilar J, Foffani G (2014) Cortical reorganization after spinal cord injury: always for good? Neuroscience 283:78-94. CrossRef Medline

Murray KC, Nakae A, Stephens MJ, Rank M, D’Amico J, Harvey PJ, Li X, Harris RL, Ballou EW, Anelli R, Heckman CJ, Mashimo T, Vavrek R, Sanelli L, Gorassini MA, Bennett DJ, Fouad K (2010) Recovery of motoneuron and locomotor function after spinal cord injury depends on constitutive activity in 5-HT2C receptors. Nat Med 16:694-700. CrossRef Medline

Neafsey EJ, Bold EL, Haas G, Hurley-Gius KM, Quirk G, Sievert CF, Terreberry RR (1986) The organization of the rat motor cortex: a microstimulation mapping study. Brain Res 396:77-96. CrossRef Medline

Nishibe M, Barbay S, Guggenmos D, Nudo RJ (2010) Reorganization of motor cortex after controlled cortical impact in rats and implications for functional recovery. J Neurotrauma 27:2221-2232. CrossRef Medline

Nishibe M, Urban ET 3rd, Barbay S, Nudo RJ (2014) Rehabilitative training promotes rapid motor recovery but delayed motor map reorganization in a rat cortical ischemic infarct model. Neurorehabil Neural Repair. Advance online publication. Retrieved April 7, 2015. doi:10.1177/ 1545968314543499. CrossRef Medline

Nudo RJ, Friel KM (1999) Cortical plasticity after stroke: implications for rehabilitation. Rev Neurol 155:713-717. Medline

Nudo RJ, Wise BM, SiFuentes F, Milliken GW (1996a) Neural substrates for the effects of rehabilitative training on motor recovery after ischemic infarct. Science 272:1791-1794. CrossRef Medline

Nudo RJ, Milliken GW, Jenkins WM, Merzenich MM (1996b) Usedependent alterations of movement representations in primary motor cortex of adult squirrel monkeys. J Neurosci 16:785-807. Medline

Overduin SA, d'Avella A, Carmena JM, Bizzi E (2012) Microstimulation activates a handful of muscle synergies. Neuron 76:1071-1077. CrossRef Medline

Overduin SA, d'Avella A, Carmena JM, Bizzi E (2014) Muscle synergies evoked by microstimulation are preferentially encoded during behavior. Front Comput Neurosci 8:20. CrossRef Medline

Oza CS, Giszter SF (2014) Plasticity and alterations of trunk motor cortex following spinal cord injury and non-stepping robot and treadmill training. Exp Neurol 256:57-69. CrossRef Medline

Pascual-Leone A, Nguyet D, Cohen LG, Brasil-Neto JP, Cammarota A, Hallett M (1995) Modulation of muscle responses evoked by transcranial magnetic stimulation during the acquisition of new fine motor skills. J Neurophysiol 74:1037-1045. Medline

Pascual-Leone A, Peris M, Tormos JM, Pascual AP, Catalá MD (1996) Reorganization of human cortical motor output maps following traumatic forearm amputation. Neuroreport 7:2068-2070. CrossRef Medline

Petruska JC, Ichiyama RM, Jindrich DL, Crown ED, Tansey KE, Roy RR, Edgerton VR, Mendell LM (2007) Changes in motoneuron properties and synaptic inputs related to step training after spinal cord transection in rats. J Neurosci 27:4460-4471. CrossRef Medline

Plautz EJ, Milliken GW, Nudo RJ (2000) Effects of repetitive motor training on movement representations in adult squirrel monkeys: role of use versus learning. Neurobiol Learn Mem 74:27-55. CrossRef Medline

Press WH, Teukolsky SA, Vetterling WT, Flannery BP (2007) Numerical recipes: the art of scientific computing, Ed 3. New York: Cambridge UP.

Ramanathan D, Conner JM, Tuszynski MH (2006) A form of motor cortical plasticity that correlates with recovery of function after brain injury. Proc Natl Acad Sci U S A 103:11370-11375. CrossRef Medline

Rijntjes M, Tegenthoff M, Liepert J, Leonhardt G, Kotterba S, Müller S, Kiebel S, Malin JP, Diener HC, Weiller C (1997) Cortical reorganization in patients with facial palsy. Ann Neurol 41:621-630. CrossRef Medline

Sanes JN, Suner S, Lando JF, Donoghue JP (1988) Rapid reorganization of adult rat motor cortex somatic representation patterns after motor nerve injury. Proc Natl Acad Sci U S A 85:2003-2007. CrossRef Medline
Sanes JN, Suner S, Donoghue JP (1990) Dynamic organization of primary motor cortex output to target muscles in adult rats. I. Long-term patterns of reorganization following motor or mixed peripheral nerve lesions. Exp Brain Res 79:479-491. Medline

Schieber MH (2001) Constraints on somatotopic organization in the primary motor cortex. J Neurophysiol 86:2125-2143. Medline

Schieber MH, Deuel RK (1997) Primary motor cortex reorganization in a longterm monkey amputee. Somatosens Mot Res 14:157-167. CrossRef Medline

Schweighofer N, Choi Y, Winstein C, Gordon J (2012) Task-oriented rehabilitation robotics. Am J Phys Med Rehabil 91:S270-S279. CrossRef Medline

Scott SH (2012) The computational and neural basis of voluntary motor control and planning. Trends Cogn Sci 16:541-549. CrossRef Medline

Stelzner DJ, Ershler WB, Weber ED (1975) Effects of spinal transection in neonatal and weanling rats: survival of function. Exp Neurol 46:156-177. CrossRef Medline

Tandon S, Kambi N, Mohammed H, Jain N (2013) Complete reorganization of the motor cortex of adult rats following long-term spinal cord injuries. Eur J Neurosci 38:2271-2279. CrossRef Medline

Todorov E (2004) Optimality principles in sensorimotor control. Nat Neurosci 7:907-915. CrossRef Medline

Todorov E, Li W, Pan X (2005) From task parameters to motor synergies: a hierarchical framework for approximately-optimal control of redundant manipulators. J Robot Syst 22:691-710. CrossRef Medline

Toldi J, Laskawi R, Landgrebe M, Wolff JR (1996) Biphasic reorganization of somatotopy in the primary motor cortex follows facial nerve lesions in adult rats. Neurosci Lett 203:179-182. CrossRef Medline

Tresch MC, Jarc A (2009) The case for and against muscle synergies. Curr Opin Neurobiol 19:601-607. CrossRef Medline

Tresch MC, Saltiel P, d'Avella A, Bizzi E (2002) Coordination and localization in spinal motor systems. Brain Res Brain Res Rev 40:66-79. CrossRef Medline

Tyč F, Boyadjian A (2011) Plasticity of motor cortex induced by coordination and training. Clin Neurophysiol 122:153-162. CrossRef Medline

Tyc F, Boyadjian A, Devanne H (2005) Motor cortex plasticity induced by extensive training revealed by transcranial magnetic stimulation in human. Eur J Neurosci 21:259-266. CrossRef Medline

Udoekwere UI (2010) Identifying the substrate for successful robot rehabilitation in adult rats spinalized as neonates: the role of the trunk in locomotor recovery after complete low-thoracic transection. $\mathrm{PhD}$ Thesis, Drexel University.

Udoekwere UI, Ramakrishnan A, Mbi L, Giszter SF (2006) Robot application of elastic fields to the pelvis of the spinal transected rat: a tool for detailed assessment and rehabilitation. Conf Proc IEEE Eng Med Biol Soc 1:3684-3687. CrossRef Medline

Udoekwere UI, Oza CS, Giszter SF (2014) A pelvic implant orthosis in rodents, for spinal cord injury rehabilitation, and for brain machine interface research: construction, surgical implantation and validation. J Neurosci Methods 222:199-206. CrossRef Medline

Wada N, Kanda K (2001) Neuronal pathways from group-I and -II muscle afferents innervating hindlimb muscles to motoneurons innervating trunk muscles in low-spinal cats. Exp Brain Res 136:263-268. CrossRef Medline

Wada N, Shikaki N, Tokuriki M, Kanda K (1999) Neuronal pathways from lowthreshold hindlimb cutaneous afferents to motoneurons innervating trunk muscles in low-spinal cats. Exp Brain Res 128:543-549. CrossRef Medline

Wada N, Kanda Y, Tokuriki M, Kanda K (2000) Neuronal pathways from lowthreshold muscle and cutaneous afferents innervating tail to trunk muscle motoneurons in the cat. J Comp Physiol A 186:771-779. CrossRef Medline

Wada N, Takahashi K, Kanda K (2003) Synaptic inputs from low threshold afferents of trunk muscles to motoneurons innervating the longissimus lumborum muscle in the spinal cat. Exp Brain Res 149:487-496. Medline

Winchester P, McColl R, Querry R, Foreman N, Mosby J, Tansey K, Williamson J (2005) Changes in supraspinal activation patterns following robotic locomotor therapy in motor-incomplete spinal cord injury. Neurorehabil Neural Repair 19:313-324. CrossRef Medline

Wu CW, Kaas JH (1999) Reorganization in primary motor cortex of primates with long-standing therapeutic amputations. J Neurosci 19:76797697. Medline

Yang YS, Koontz AM, Triolo RJ, Mercer JL, Boninger ML (2006) Surface electromyography activity of trunk muscles during wheelchair propulsion. Clin Biomech (Bristol, Avon) 21:1032-1041. CrossRef Medline

Zomlefer MR, Provencher J, Blanchette G, Rossignol S (1984) Electromyographic study of lumbar back muscles during locomotion in acute high decerebrate and in low spinal cats. Brain Res 290:249-260. CrossRef Medline 